\title{
Design and Analysis of AIGaN/InGaN/GaN and InAIN/InGaN/GaN HEMTs for High-Power Wide Bandwidth Applications
}

REVATHY A ( $\sim$ arevathynew@gmail.com )

SRM Institute of Science and Technology https://orcid.org/0000-0001-5938-9143

C.S. Boopathi

SRM Institute of Science and Technology

D. Nirmal

Karunya Institute of technology and Science: Karunya Institute of Technology and Sciences

\section{Manuscript}

Keywords: Composite channel, InGaN, high-frequency, stable transconductance, wide bandwidth

Posted Date: February 4th, 2021

DOl: https://doi.org/10.21203/rs.3.rs-163255/v1

License: (c) (i) This work is licensed under a Creative Commons Attribution 4.0 International License.

Read Full License 


\title{
Design and analysis of AIGaN/InGaN/GaN and InAIN/InGaN/GaN HEMTs for high-power wide bandwidth applications
}

\author{
A. Revathy $^{1 *}$ C.S. Boopathi ${ }^{2}$ D. Nirmal ${ }^{3}$ \\ ${ }^{1 * \& 2}$ Department of Electrical and Electronics Engineering, SRM Institute of Science and Technology, Chennai, \\ India-603 203. \\ ${ }^{3}$ Department of Electronics and Communication Engineering, Karunya Institute of Technology and Sciences, \\ Karunya Nagar, Coimbatore, Tamil Nadu, India- 641114 \\ Email: arevathynew@gmail.com
}

\begin{abstract}
:
We present the stable transconductance operation of InGaN/GaN composite channel based HEMTs. $\mathrm{L}_{\mathrm{G}}=55 \mathrm{~nm} \mathrm{AlGaN/InGaN/GaN}$ (Device A) and InAlN/InGaN/GaN (Device B) HEMTs were proposed and investigated its operational characteristics using numerical simulation. Existence of deeper potential well, the proposed HEMTs possesses high 2DEG (twodimensional electron gas) density, enhanced electron confinement, and improved electron mobility. As a result, the device shows enhanced current density, and high linearity operation. Furthermore, $\mathrm{Al}_{0.04} \mathrm{Ga}_{0.96} \mathrm{~N}$ superlative back-barrier significantly reduces the buffer leakage current resulting in improved breakdown voltage $\left(\mathrm{V}_{\mathrm{BR}}\right)$. The proposed device A (device $\mathrm{B}$ ) exhibited 2.81 (5) A/mm of output current density, 0.669 (0.7273) S/mm, 4 (7) V of GVS (gate voltage swing), 55.3 (43.5) $\mathrm{V}$ of breakdown voltage, and 252/263 (275/289) $\mathrm{GHz}$ of $\mathrm{F}_{\mathrm{T}} / \mathrm{F}_{\mathrm{MAX}}$. This excellent device performances illustrates the potential of InGaN/GaN channel HEMTs for future wide-band telecommunication, radio astronomy, radar and space applications.
\end{abstract}

\section{Keywords:}

Composite channel; InGaN; high-frequency; stable transconductance; wide bandwidth;

\section{Introduction:}

The III-nitride heterostructure based devices have been proved its excellent performance for high power millimeter wave electronics [1-3]. Polarization induced 2D electron gas (2DEG), wide bandgap, and high mobility of III-nitride heterostructures makes the devices for high-power density microwave applications. The operating frequency of the GaN-based HEMTs is significantly improved by shrink the device size into deep sub-micron for low parasitic and second order effects [4-20]. However, the short distance between the gate to drain degrade the linearity of the device. The non-linear behavior of the short channel HEMTs mainly because of extrinsic transconductance $\left(\mathrm{G}_{\mathrm{M}}\right)$ drops quickly after reaching its peak value at high gate-source bias with increasing drain current. Increasing the source access resistance with the drain current 
is the major source for $\mathrm{G}_{\mathrm{M}}$ drop-off [21-23]. The optical phonon emission, interface roughness, and self-heating are also affecting the stable $G_{M}$ characteristics [24-27]. Furthermore, the maximum output current density of GaN-channel based devices is still below the theoretical limit.

The drain current density of the HEMTs is improved by the $n+\mathrm{GaN}$ source/drain contacts [28]. However, it lowering the breakdown voltage $\left(\mathrm{V}_{\mathrm{BR}}\right)$ and hence the device is not suitable for high power amplifier applications. Therefore, the exploitation of advanced device structure is required to break through the limitation of conventional GaN channel-based devices. The planar nano strip channel MOSHEMT had shown the stable transconductance [29]. However, the peak transconductance $\left(\mathrm{G}_{\mathrm{M}}\right)$ and cut-off frequency of the device are lower than conventional HEMT. Yachao Zhang et al. presented the InGaN double channel (DC) HEMT on Sapphire substrate [30] and the device shown stable transconductance in spite of low $\mathrm{F}_{\mathrm{T}} / \mathrm{F}_{\mathrm{MAX}}$. In recent years, InGaN channel based HEMTs proven its superior performance than conventional GaN channel based HEMTs [30-34].

The lower electron mass and narrow bandgap of InGaN material enhance the carrier mobility and creates the deeper potential well with wide bandgap material. And also, the InGaN channel HEMTs had demonstrated superior performance at high temperature, current collapse reduction, low noise, and suppression of virtual gate effects [30-34]. However, the breakdown voltage of the InGaN channel-based devices is relatively lower than GaN channel based HEMTs because of narrow bandgap.

In this work, we propose composite channel $\mathrm{In}_{0.1} \mathrm{Ga}{ }_{0.9} \mathrm{~N} / \mathrm{GaN}$ based HEMTs on sapphire substrate with $\mathrm{Al}_{0.04} \mathrm{Ga} 0.96 \mathrm{~N}$ superlative back-barrier, which benefiting the advantages of both InGaN and $\mathrm{GaN}$ material property results in high breakdown voltage, high linearity, high output current density, and high $\mathrm{F}_{\mathrm{T}} / \mathrm{F}_{\max }$. We investigate the composite channel based HEMT with two different barrier material $\left(\mathrm{Al}_{0.3} \mathrm{Ga}_{0.7} \mathrm{~N}\right.$ and $\left.\mathrm{In}_{0.17} \mathrm{Al}_{0.83} \mathrm{~N}\right)$ and the comparative results are presented. The proposed device characteristics are analyzed using the ATLAS TCAD simulator by incorporating polarization models, SRH recombination models, nitride low and high filed mobility models, and Selberherr's impact ionization models. Composite channel based HEMT with $55 \mathrm{~nm}$ T-shaped gate structure shows very high drain current density, improved breakdown voltage, excellent $\mathrm{F}_{\mathrm{T}} / \mathrm{F}_{\mathrm{MAX}}$ along with stable transconductance for the wide range of gate bias than conventional GaN-based HEMTs.

\section{Device description, simulation models, and material parameters}

Composite channel based $\mathrm{AlGaN} / \mathrm{InGaN} / \mathrm{GaN} / \mathrm{AlGaN}$ heterostructure on a sapphire substrate (Device A) shown in Fig.1(a). InAlN/InGaN/GaN/AlGaN HEMT (Device B) is shown in Fig.1(b). The barrier had a thickness of $11 \mathrm{~nm}$ and $1000 \mathrm{~nm} \mathrm{Al}_{0.04} \mathrm{Ga}_{0.96} \mathrm{~N}$ buffer as a natural back-barrier. Composite channel HEMT had $4 \mathrm{~nm} \mathrm{In}_{0.1} \mathrm{Ga}_{0.9} \mathrm{~N}$ and $5 \mathrm{~nm} \mathrm{GaN}$ channel layers. Low $\mathrm{Al}$ content $\mathrm{Al}_{0.04} \mathrm{Ga}_{0.96} \mathrm{~N}$ was used as a back-barrier to avoid excessive stress in the $\mathrm{GaN}$ layer and helped the device for enhanced carrier confinement in the channel. A $55 \mathrm{~nm}$ foot length 
T-shaped gate region is formed with $100 \mathrm{~nm}$ stem height for very low the gate resistance $\mathrm{R}_{\mathrm{G}}$. Both devices are passivated by $50 \mathrm{~nm} \mathrm{Si}_{3} \mathrm{~N}_{4}$ for eliminating surface trap related issues. The Schottky gate contact was realized by $\mathrm{Au} / \mathrm{Ni}$ metal stack and $\mathrm{Ti} / \mathrm{Au}$ metal stacks were defined as source/drain ohmic contacts.

TCAD simulation energy band diagram of the proposed HEMTs are displayed in Fig.2(a) and Fig.2(b) respectively. The InAlN/InGaN heterostructure based device had a deeper well, and also the inclusion of a $5 \mathrm{~nm}$ GaN layer along with $\mathrm{InGaN}$ channel results in uniform electron distribution in the $2 \mathrm{DEG}$.

(a)

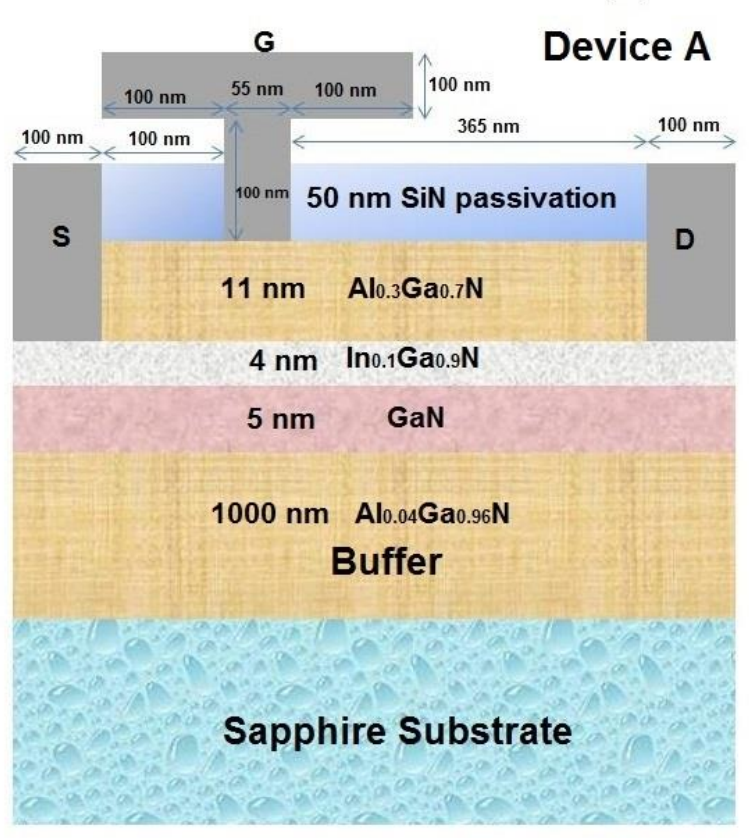

(b)

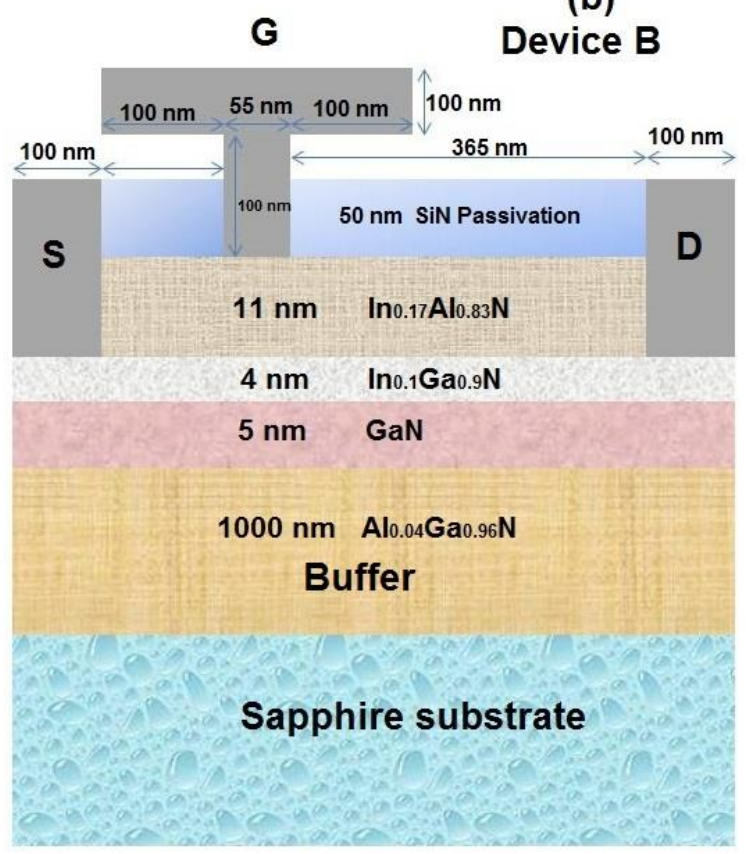

Figure 1. (a) Proposed device A (b) Proposed device B 

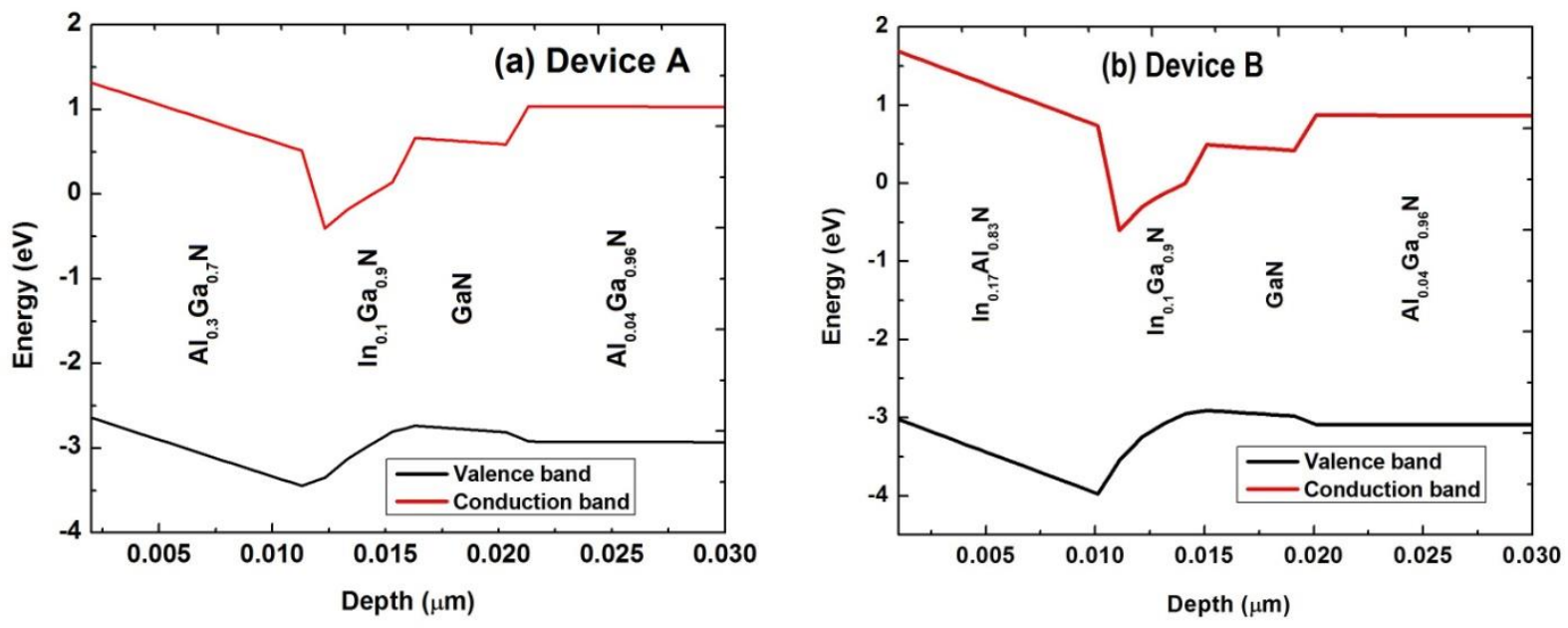

Figure 2. (a) Band diagram of Device A (b) Band diagram of Device B
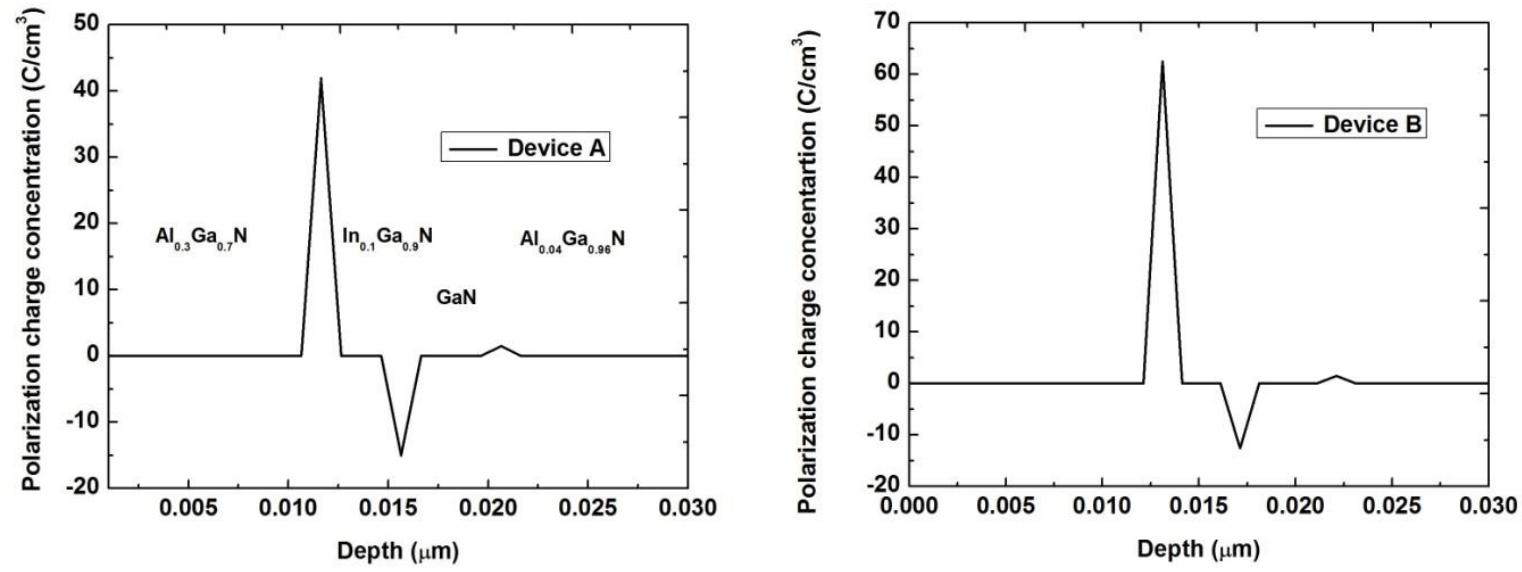

Figure 3. Polarization charge details of (a) AIGaN/InGaN/GaN/AIGaN heterostructure (b) InAIN/InGaN/GaN/AIGaN heterostructure. 
(a)

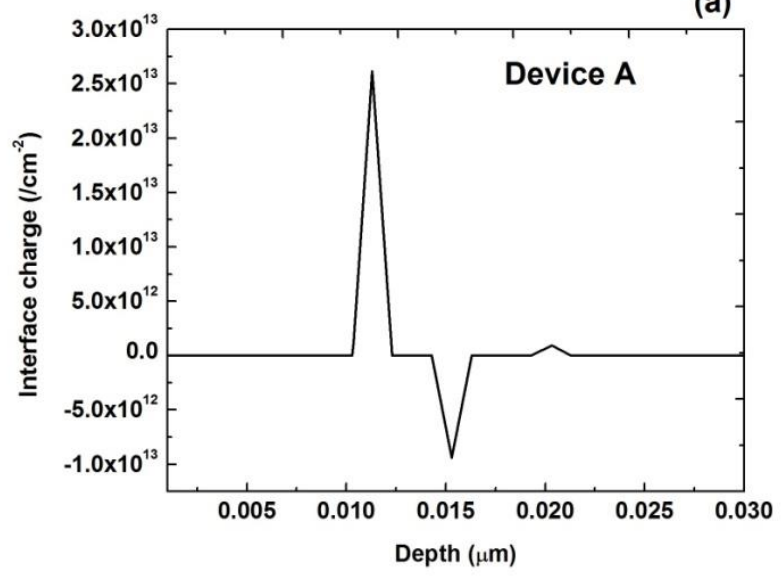

(b)

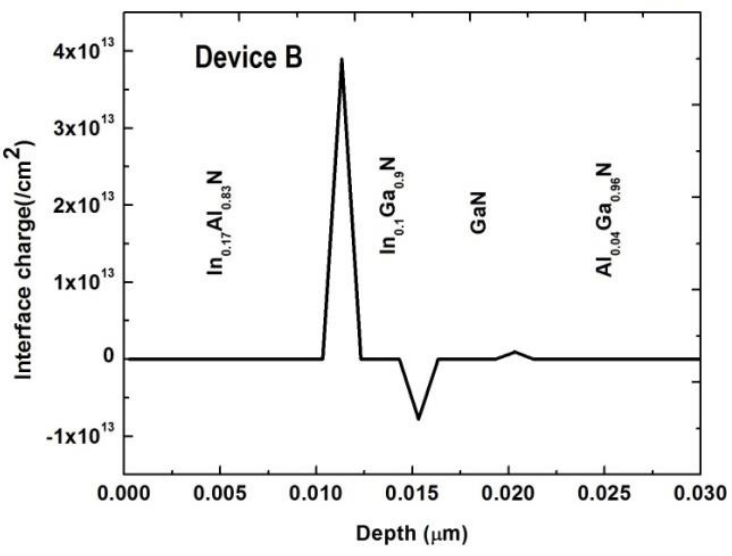

Figure 4. Interface charge details of (a) Device A (b) Device B

The proposed and conventional HEMTs are simulated using ATLAS two-dimensional (2D) TCAD simulator by incorporating GaN polarization model, nitride low field mobility model, nitride high field mobility model, Fermi-Dirac model, Shockley-Read-Hall (SRH) recombination model and, Selberherr's impact ionization models.

The polarization models for the III-nitride heterostructure are essential for TCAD simulation. The spontaneous $\left(\mathrm{P}_{\mathrm{SP}}\right)$ and piezoelectric polarization $\left(\mathrm{P}_{\mathrm{PE}}\right)$ models are defined in the physics section. The fixed polarization charge density at the III-nitride interface is obtained from $\mathrm{P}_{\mathrm{SP}}$ and $\mathrm{P}_{\mathrm{PE}}[35]$.

$P_{\text {total }}=\left[P_{P E}(\right.$ bottom $)+P_{S P}($ bottom $\left.)\right]-\left[P_{P E}(\right.$ top $)+P_{S P}($ top $\left.)\right]$

The interface charge density is given by [36-37]:

$\rho P=-\nabla \cdot P=-\frac{\partial P}{\partial Z}$

Table 1. Polarization parameters of III-nitride binary alloys [38].

\begin{tabular}{|l|c|l|l|l|}
\hline Parameter & Units & GaN & AlN & InN \\
\hline $\begin{array}{l}\text { Lattice } \\
\text { constant } \\
\left(a_{0}\right)\end{array}$ & $A^{\circ}$ & 3.189 & 3.112 & 3.548 \\
\hline $\begin{array}{l}\text { Lattice } \\
\text { constant } \\
(a)\end{array}$ & $A^{\circ}$ & 3.197 & 3.108 & 4.58 \\
\hline $\begin{array}{l}\text { Spontaneous } \\
\text { Polarization }\end{array}$ & $C / m^{2}$ & -0.034 & -0.09 & -0.042 \\
\hline
\end{tabular}




\begin{tabular}{|l|l|l|l|l|}
\hline \multicolumn{1}{|c|}{$\left(P_{S P}\right)$} & & & & \\
\hline $\begin{array}{l}\text { Piezoelectric } \\
\text { const. }\left(e_{33}\right)\end{array}$ & $C / m^{2}$ & 0.67 & 1.5 & 0.81 \\
\hline $\begin{array}{l}\text { Piezoelectric } \\
\text { const. }\left(e_{31}\right)\end{array}$ & $C / m^{2}$ & -0.34 & -0.53 & -0.41 \\
\hline $\begin{array}{l}\text { Elastic } \\
\text { constants } \\
\left(C_{13}\right)\end{array}$ & $G P a$ & 68 & 94 & 70 \\
\hline $\begin{array}{l}\text { Elastic } \\
\text { constants } \\
\left(C_{33}\right)\end{array}$ & $G P a$ & 354 & 377 & 205 \\
\hline
\end{tabular}

The piezoelectric polarization of wurtzite III-nitride binary alloys are obtained from [38]:

$$
P_{P E}=2 \frac{a-a_{0}}{a_{0}}\left(e_{31}-e_{33} \frac{C_{13}}{C_{33}}\right)
$$

Where $C_{13}$ and $C_{33}$ are elastic constants. And $a_{0}$ and $a$ represent relaxed and strained crystal lattice structure hexagonal edge respectively. The $\mathrm{PSP}_{\mathrm{SP}}$ and $\mathrm{PPE}_{\mathrm{PE}}$ constants of $\mathrm{Al}_{\mathrm{x}} \mathrm{Ga}_{1-\mathrm{x}} \mathrm{N}, \mathrm{In}_{1-\mathrm{x}} \mathrm{Al}_{\mathrm{x}} \mathrm{N}$, and $\operatorname{In}_{\mathrm{x}} \mathrm{Ga}_{1-\mathrm{x}} \mathrm{N}$ ternary alloys are obtained from second-order polynomial regressions [39]. Table 1 presents the polarization parameters of III-nitride binary alloys.

The doping and temperature-dependent nitride low and high field mobility models are used in this simulation as follows [40]:

$$
\mu_{0}(T, N)=\mu_{\min }\left(\frac{T}{300}\right)^{\beta_{1}}+\frac{\left(\mu_{\max }-\mu_{\min }\right)\left(\frac{T}{300}\right)^{\beta_{2}}}{1+\left[\frac{N}{N_{r e f}\left(\frac{T}{300}\right)^{\beta_{3}}}\right]^{\alpha(T / 300)^{\beta_{4}}}}
$$

Where $T$ is the temperature, $N$ is the total doping density, and $\alpha, \beta_{1}, \beta_{2}, \beta_{3}, \beta_{4}, \mu_{\min }, \mu_{\max }$, and $N_{\text {ref }}$ are fitting parameters. And the temperature-dependent nitride high field mobility model as follows [40]:

$$
\mu=\frac{\mu_{0}(T, N)+v^{s a t} \frac{E^{n 1-1}}{E_{C}^{n 1}}}{1+a\left(\frac{E}{E_{C}}\right)^{n 2}+\left(\frac{E}{E_{C}}\right)^{n 1}}
$$

Where $\mu_{0}$ is the low field mobility as expressed in (4), $E$ is the electric field, $v^{\text {sat }}, E_{c}, a, n 1$, and $n 2$ are fitting parameters of Faramand modifier Thomas model for nitrides.

The trap state is created within the bandgap due to crystal lattice defects or dopants. To capture the trap-assisted recombination, the SRH model is considered [40]. 


$$
R_{n e t}^{S R H}=\frac{n-n_{i e}^{2}}{\tau_{p}\left[p+n_{i e} \exp \left(\frac{-E_{t r a p}}{K T}\right)\right]+\tau_{n}\left[p+n_{i e} \exp \left(\frac{-E_{t r a p}}{K T}\right)\right]^{\prime}}
$$

Where $\tau_{p}$ and $\tau_{n}$ are the holes and electrons lifetimes and intrinsic carrier concentration is denoted by $n_{i e}$. Intrinsic Fermi level to trap energy level is $E_{\text {trap }}$ and $T$ is the temperature. The various material parameters use in this work is displayed in Table.2.

Fig.3 and Fig.4 shows the polarization charge concentration and interface charge details respectively. Device B had shown a very high polarization charge concentration $\left(62.5 \mathrm{C}^{\mathrm{cm}} \mathrm{cm}^{3}\right)$ due to stronger polarization of InAlN/InGaN heterostructure. And relatively narrow bandgap of the InGaN material yield high 2DEG density in the proposed HEMT and the low effective electron mass of InGaN channel improved the mobility of carriers. Meanwhile, to improve the breakdown voltage of the narrow bandgap channel device, proposed HEMTs had composite channel InGaN/GaN with $\mathrm{AlGaN}$ superlative back-barrier proposed in this work.

Table 2. Parameters used in this simulation. The Ternary alloys $\mathrm{Al}_{\mathrm{x}} \mathrm{Ga1-x} \mathrm{N}, \mathrm{In}_{1-\mathrm{x}} \mathrm{Al} \mathrm{I}_{\mathrm{x}} \mathrm{N}$, and $\mathrm{In}_{\mathrm{x}} \mathrm{Ga}_{1-\mathrm{x}} \mathrm{N}$ parameters are obtained from the material composition $\mathrm{x}$ is interpolated by a quadratic function of the basic materials [41].

\begin{tabular}{|l|c|l|l|l|}
\hline Parameter & Unit & GaN & AlN & InN \\
\hline $\begin{array}{l}\text { Permittivity } \\
(\varepsilon)\end{array}$ & - & 8.9 & 8.5 & 15.3 \\
\hline $\begin{array}{l}\text { Energy band } \\
\text { gap }\left(E_{g}\right)\end{array}$ & $e V$ & 3.4 & 6.2 & 0.69 \\
\hline $\begin{array}{l}\text { Low field } \\
\text { electron } \\
\text { mobility }\left(\mu_{n}\right)\end{array}$ & $\mathrm{cm}^{2} v^{-1} s^{-1}$ & 1600 & 683 & 10200 \\
\hline $\begin{array}{l}\text { Saturation } \\
\text { velocity } \\
\left(v_{s a t}\right)\end{array}$ & $\mathrm{cm} / s$ & $3 \times 10^{7}$ & $3.7 \times 10^{7}$ & $5 \times 10^{7}$ \\
\hline $\begin{array}{l}\text { Effective } \\
\text { conduction } \\
\text { band density } \\
\text { of states }\left(\mathrm{N}_{\mathrm{C}}\right) \\
(300 \mathrm{~K})\end{array}$ & $\mathrm{cm}^{-3}$ & $2.3 \times 10^{18}$ & $6.3 \times 10^{18}$ & $9 \times 10^{17}$ \\
\hline $\begin{array}{l}\text { Effective } \\
\text { valence band } \\
\text { density of } \\
\text { states (Nv) } \\
(300 \mathrm{~K})\end{array}$ & $\mathrm{cm}^{-3}$ & $4.6 \times 10^{19}$ & $4.8 \times 10^{20}$ & $5.3 \times 10^{19}$ \\
\hline $\begin{array}{l}\text { Effective } \\
\text { electron mass } \\
\left(m_{e}\right)\end{array}$ & $\mathrm{Kg}$ & $0.2 \mathrm{~m}_{0}$ & $0.4 \mathrm{~m}_{0}$ & $0.11 \mathrm{~m}_{0}$ \\
\hline
\end{tabular}




\section{Results and Discussions}

The I-V characteristics of $\mathrm{L}_{\mathrm{G}} 55 \mathrm{~nm}$ proposed HEMTs are shown in Fig.5 (a) and (b) respectively. Device A shown a peak drain current density (IDS) of $2.614 \mathrm{~A} / \mathrm{mm}$ at $1 \mathrm{~V}$ gate bias $\left(\mathrm{V}_{\mathrm{GS}}\right)$ and the Device $\mathrm{B}$ had shown $3.92 \mathrm{~A} / \mathrm{mm}$ at $\mathrm{V}_{\mathrm{GS}}=1 \mathrm{~V}$. The high sheet charge density and enhanced carrier confinement of InAlN/InGaN/GaN HEMT (Device B) shown very high output current density than AlGaN/InGaN/GaN HEMT (Device B). Fig.6 shows the transfer characteristics of the HEMTs. The proposed devices had shown a stable transconductance with $4 \mathrm{~V}$ gate voltage swing (GVS) and $0.669 \mathrm{~S} / \mathrm{mm}$ of $\mathrm{G}_{\max }$ for Device A and $7 \mathrm{~V}$ of GVS and $0.72 \mathrm{~S} / \mathrm{mm}$ of for Device for Device B. Gate voltage swing defined at $20 \%$ drop in transconductance $\left(\mathrm{G}_{\max }\right)$. The ultra-high stable transconductance results from enhanced and uniform carrier confinement of composite channels. The additional AlGaN superlative back-barrier elevates the carrier confinement even better. This excellent improvement in linearity strongly indicates that the merits of proposed HEMTs for widebandwidth applications.

The simulation models are validated against the experimental results of $\mathrm{L}_{\mathrm{G}} 55 \mathrm{~nm}$ InAlN/GaN HEMT [19]. Fig.7 displays the validation of simulation results for V-I and transconductance characteristics against the experimental results [19]. The simulation results confirmed the great accuracy with measured results.

(a)

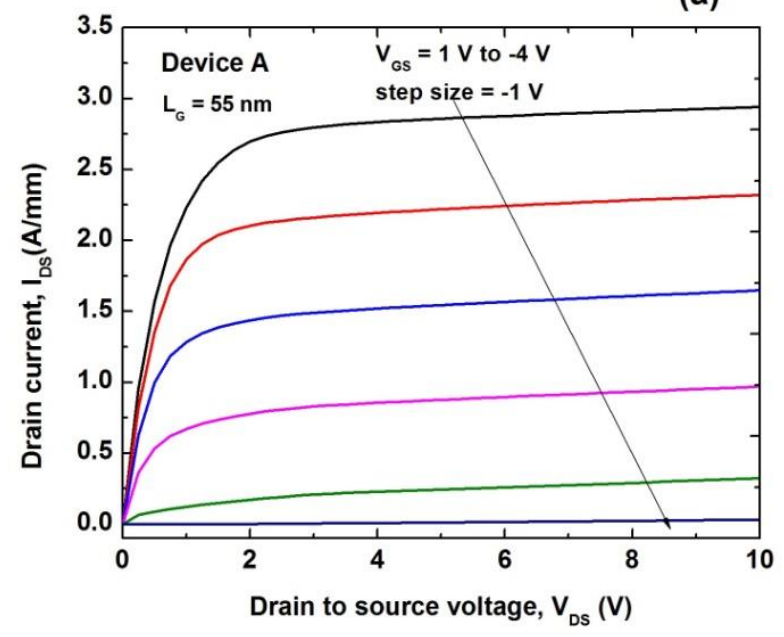

(b)

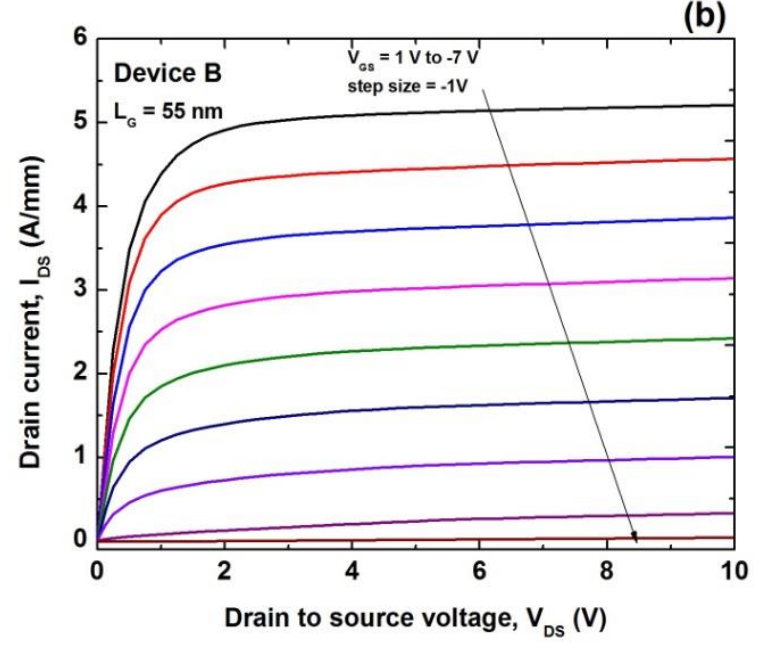

Figure 5. I-V characteristics of $L_{g} 55 \mathrm{~nm}$ HEMTs 
(a)

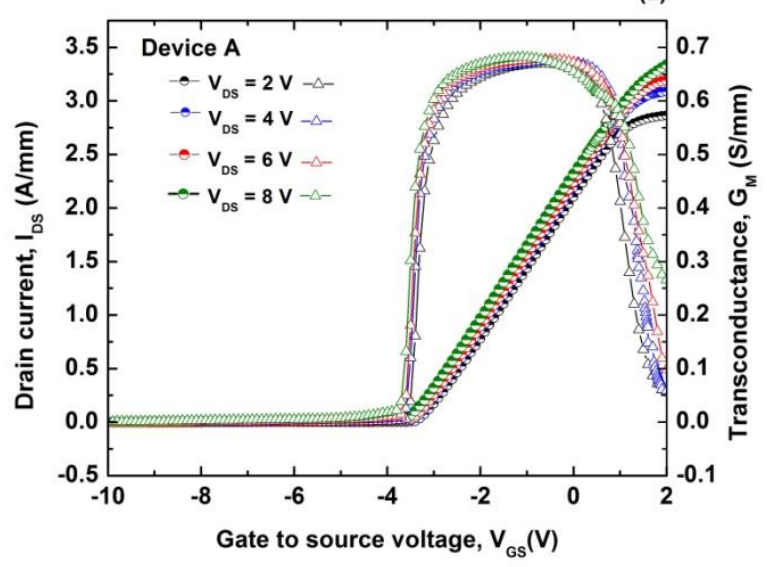

(b)

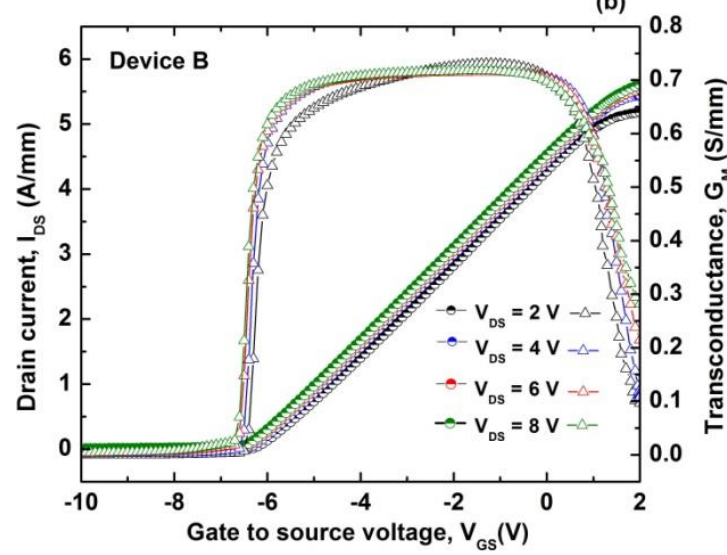

Figure 6. Transconductance characteristics of $\mathrm{Lg} 55 \mathrm{~nm}$ HEMTs

(a)

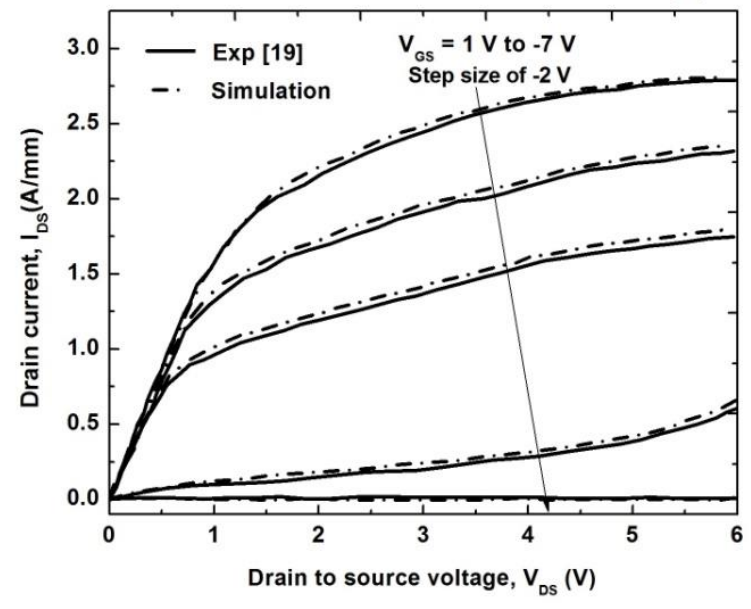

(b)

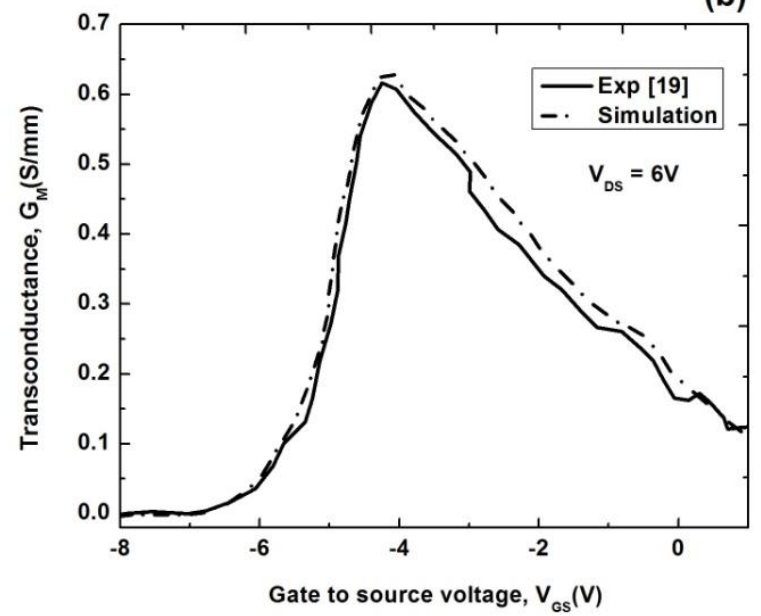

Figure 7. (a) Simulation and experimental results for V-I characteristics [19], (b) Simulation and experimental results for transconductance characteristics [19].

Fig.8 shows the sub-threshold leakage current characteristics of proposed HEMTs. Device B experiences the high leakage than Device A. The Selberherr's impact ionization model, deep donor, deep acceptor, shallow donor, SRH recombination, and augur recombination models are used in the breakdown simulation and the simulation results are plotted in Fig.9. Device A shown a breakdown voltage $\left(\mathrm{V}_{\mathrm{BR}}\right)$ of $55.3 \mathrm{~V}$ and Device $\mathrm{B}$ shown a $\mathrm{V}_{\mathrm{BR}}$ of $43.5 \mathrm{~V}$. The enhanced $V_{B R}$ of Device $A$ due to a lower drain leakage current than Device $B$. 
Fig.10 and Fig.11 shows the electric field and potential distribution of the HEMTs respectively under breakdown conditions. Enhanced carrier confinement due to composite channel and backbarrier results in very low buffer leakage currents in Device $A$ exhibited high $V_{B R}$ than conventional Device B. The $\mathrm{V}_{\mathrm{BR}}$ of the HEMTs further can be improved by the gate, drain, and source field plate techniques and Schottky source/drain contacts with compromise in cut-off frequency.

The microwave performance of the HEMTs is shown in Fig.12. Device A exhibited an $\mathrm{F}_{\mathrm{T}} / \mathrm{F}_{\mathrm{MAX}}$ of 252/263 GHz and Device B had shown an $\mathrm{F}_{\mathrm{T}} / \mathrm{F}_{\mathrm{MAX}}$ of $275 / 289 \mathrm{GHz}$. For $55 \mathrm{~nm}$ gate length, the satisfactory cut-off frequency is obtained, which can be further improved by scale down the device dimensions.

The proposed composite channel based HEMTs shown high $\mathrm{F}_{\mathrm{T}} / \mathrm{V}_{\mathrm{BR}}$ and $\mathrm{F}_{\mathrm{MAX}} / \mathrm{V}_{\mathrm{BR}}$ than the existing works. The $\mathrm{F}_{\mathrm{T}}$ and $\mathrm{F}_{\mathrm{MAX}}$ of a HEMT and RF output power of a basic power amplifier can be expressed as follow [42]:

$$
\begin{aligned}
& F_{T}=\frac{G_{M}}{2 \pi\left(C_{G D}+C_{G S}\right)} \\
& F_{T}=\frac{1}{2 \pi \tau} \\
& F_{T, \text { max }}=\frac{v_{\text {sat }}}{2 \pi L_{G}} \\
& F_{M A X}=\frac{F_{T}}{2 \sqrt{\left(R_{i}+R_{S}+R_{G}\right) /\left(R_{D S}+\left(2 \pi f_{T}\right) R_{G} C_{G D}\right)}} \\
& P_{R F}=\frac{I_{M A X}\left(V_{B R}-V_{K N E E}\right)}{8}
\end{aligned}
$$

Where $\mathrm{C}_{\mathrm{GD}}$ and $\mathrm{C}_{\mathrm{GS}}$ are gate-drain and gate-source parasitic capacitance respectively and $\tau$ represent electron transit time. Gate resistance $\left(\mathrm{R}_{\mathrm{G}}\right)$, gate length $\left(\mathrm{L}_{\mathrm{G}}\right)$, output resistance $\left(\mathrm{R}_{\mathrm{DS}}\right)$, source resistance $\left(R_{S}\right)$, and intrinsic gate resistance $\left(R_{i}\right)$ are impact the device RF performance. The proposed HEMT in this work had shown enhanced 2DEG mobility, very high output current density, an excellent stable $\mathrm{G}_{\mathrm{M}}$, high $\mathrm{V}_{\mathrm{BR}}$, and high $\mathrm{F}_{\mathrm{T}} / \mathrm{F}_{\mathrm{MAX}}$. The remarkable improvement in the device performance shows the merits of proposed HEMTs for wide-bandwidth high power millimeter-wave power applications.

Table III displays the summary of device performance of both AlGaN and InAlN barrier based composite channel HEMTs. The state-of the art of GaN-based high frequency devices are shown in Fig.13. The proposed HEMTs had shown simultaneous improvement in both $F_{T}$ and $F_{M A X}$ than existing devices. The high Johnson figure of merit ( $\left.\mathrm{JFOM}=\mathrm{F}_{\mathrm{T}} \times \mathrm{V}_{\mathrm{BR}}\right)$ and $\mathrm{F}_{\mathrm{MAX}} \times \mathrm{V}_{\mathrm{BR}}$ product of HEMTs are key parameters for high terminal voltage operation of millimeter-wave power HEMTs for delivering high output power density and high efficiency at a millimeter-wave 
frequency from equation (7) to (11). The proposed HEMTs in this work shown a high $\mathrm{F}_{\mathrm{T}} / \mathrm{V}_{\mathrm{BR}}$ and $\mathrm{F}_{\mathrm{MAX}} / \mathrm{V}_{\mathrm{BR}}$ than existing works.

(a)

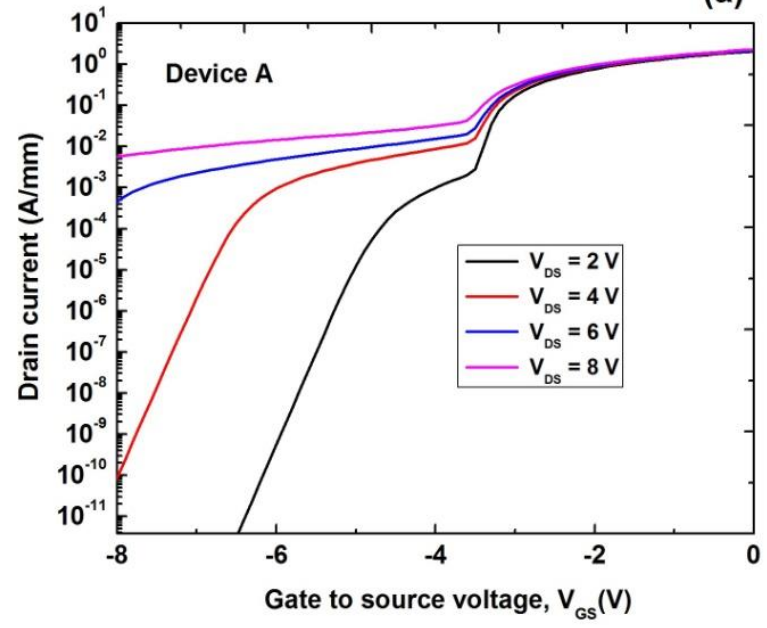

(b)

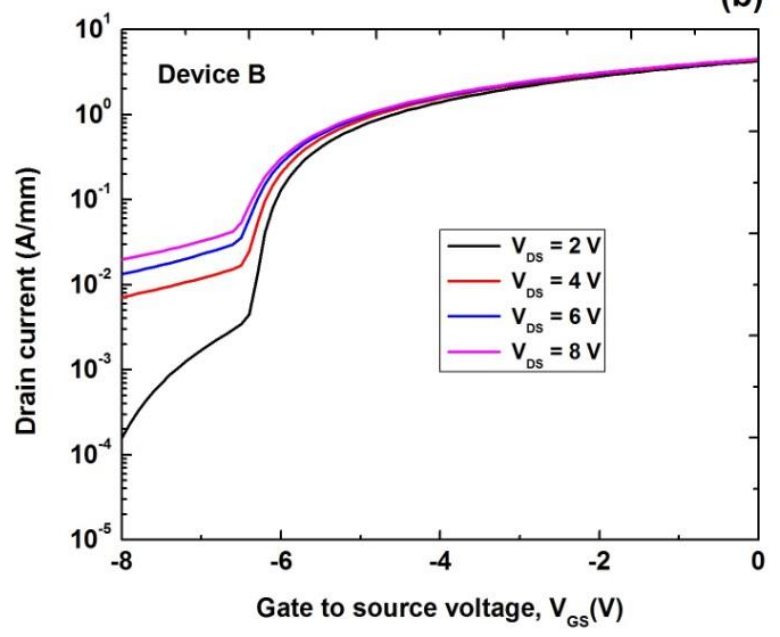

Figure 8. Log-scale plot of IDs-VGS of Lg 55 nm HEMTs

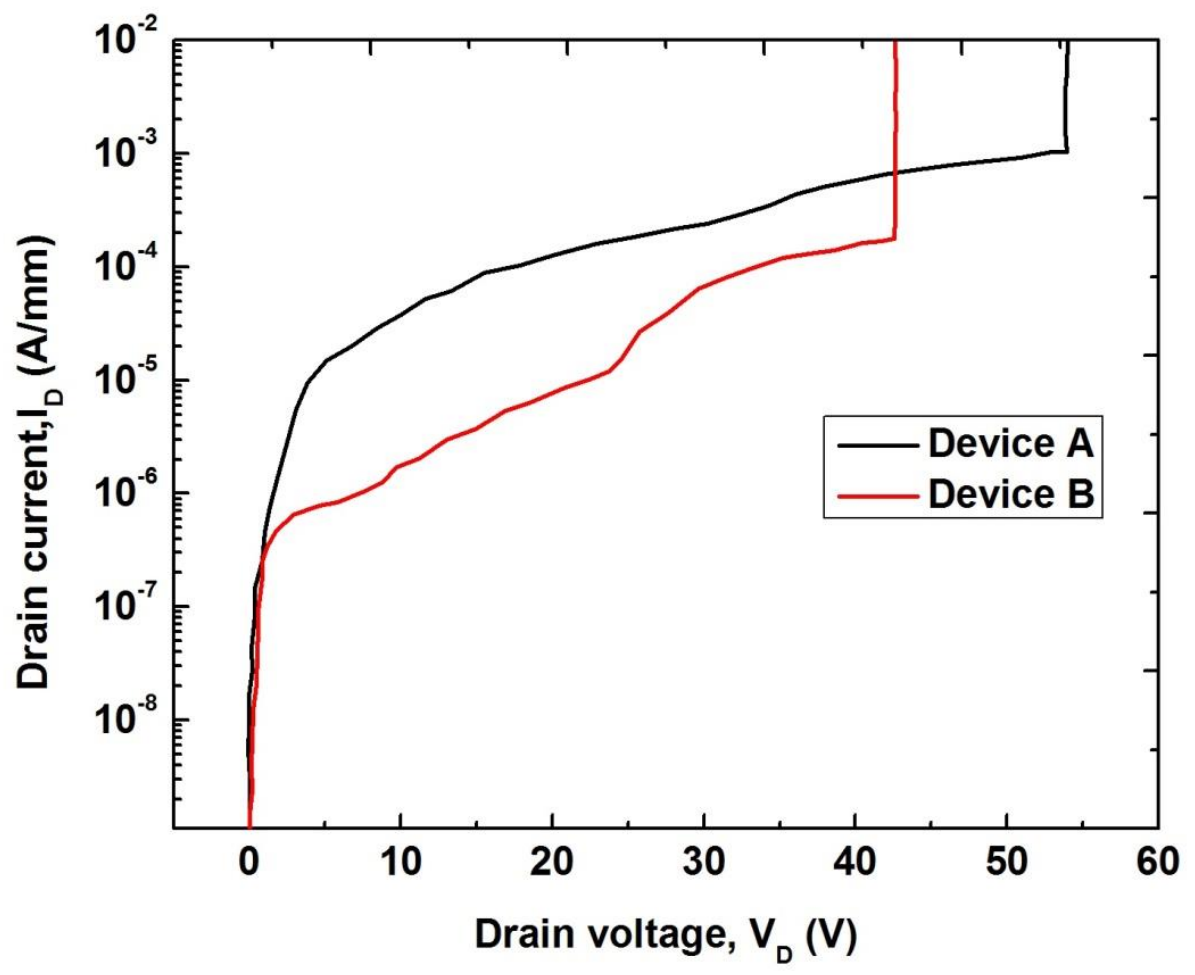

Figure 9. Breakdown characteristics 

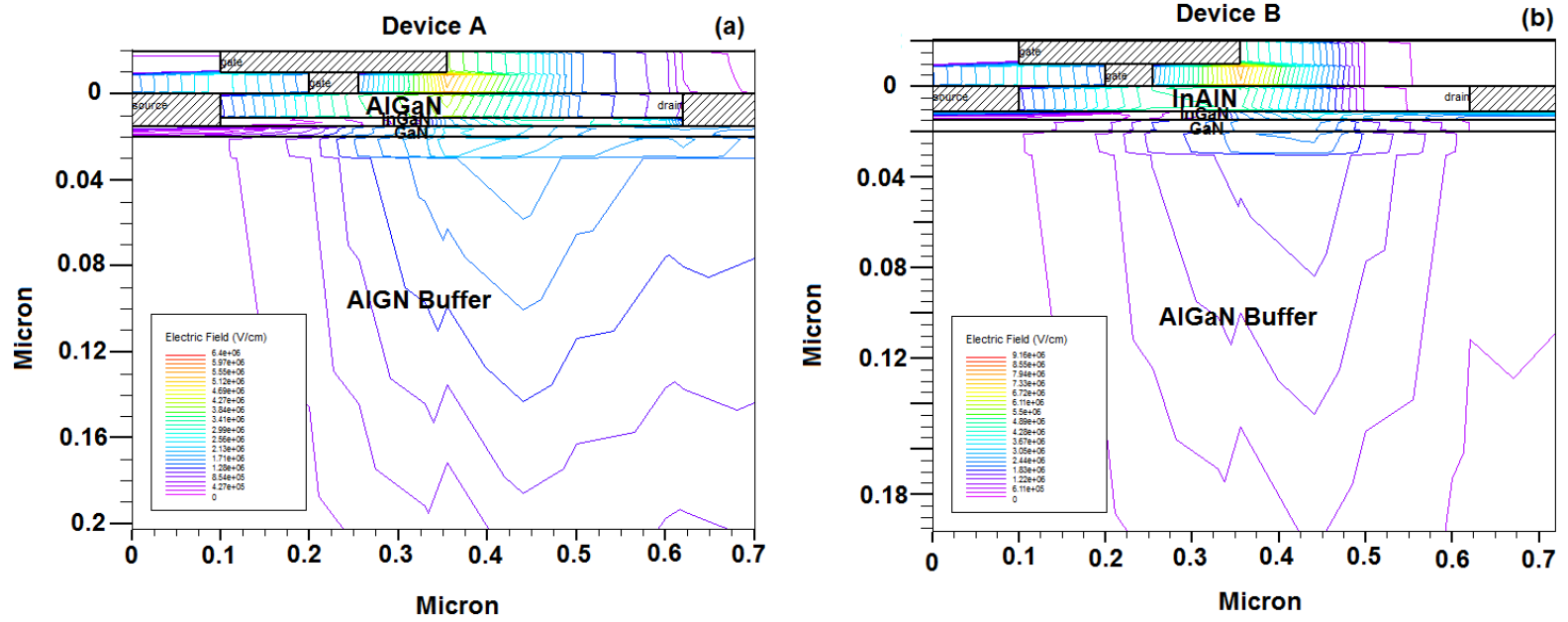

Figure 10. Electric field distribution at breakdown condition.
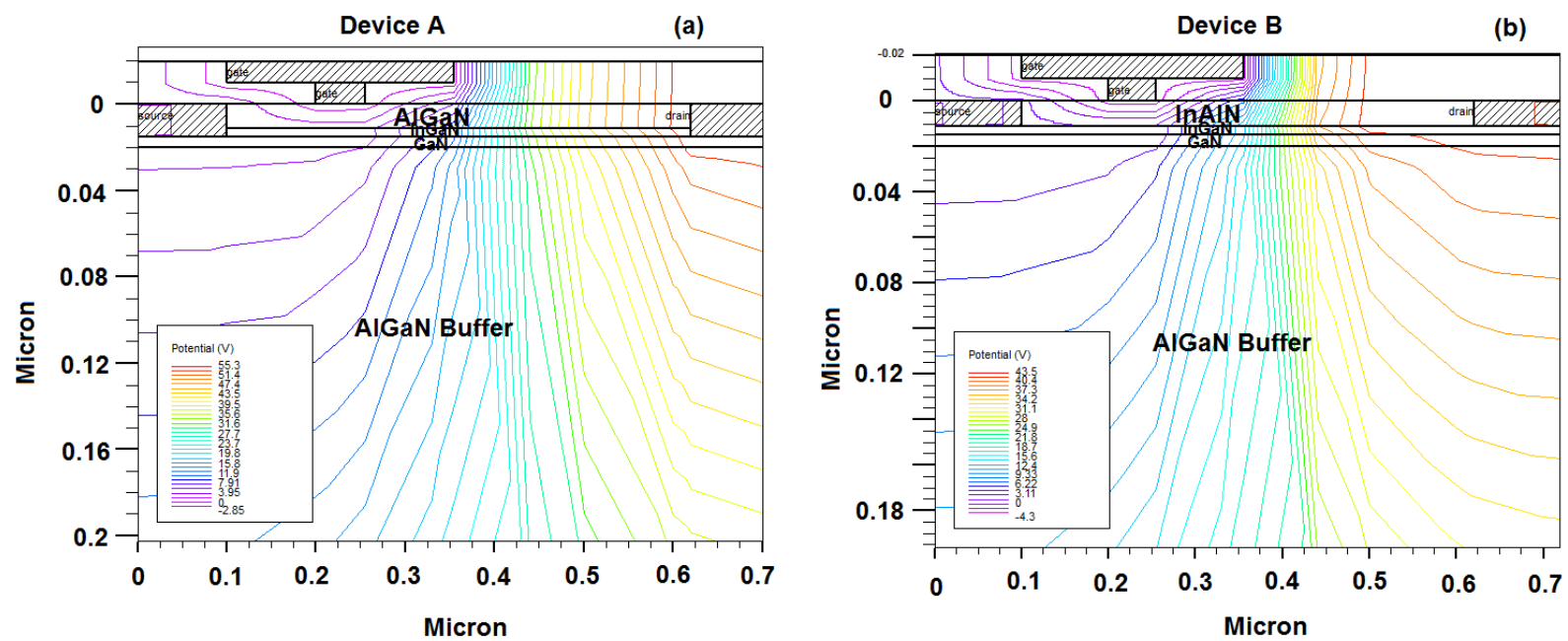

Figure 11. Potential distribution at breakdown condition. 
(a)

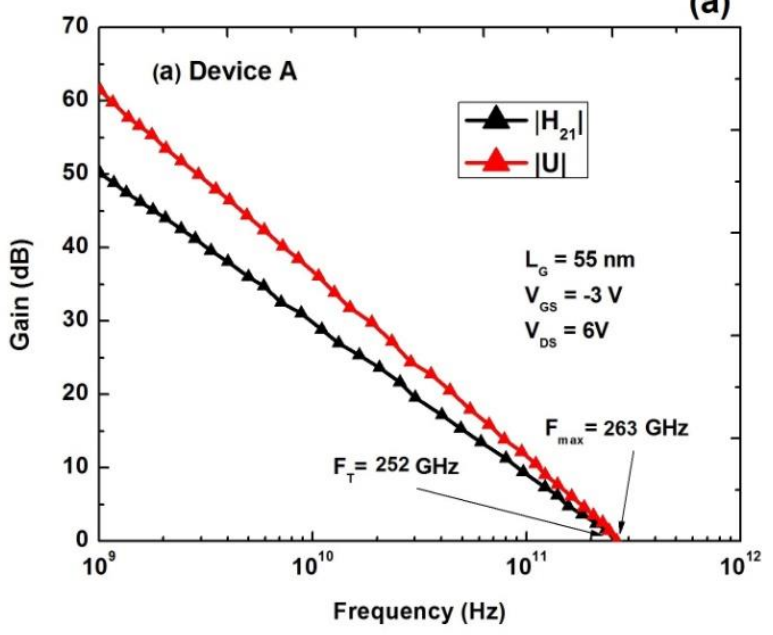

(b)

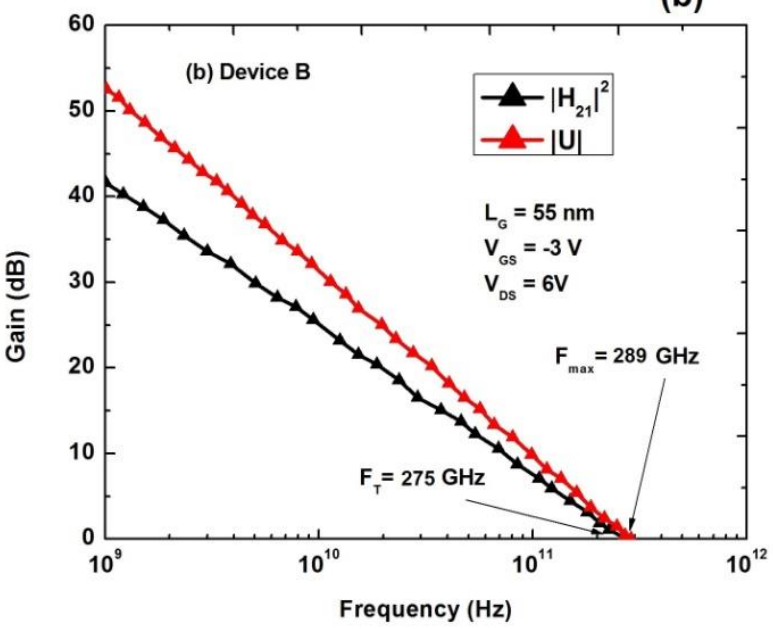

Figure 12. (a) Microwave performance of Lg $55 \mathrm{~nm}$ HEMTs

Table III. Summary of AlGaN/InGaN/GaN (Device A) and InAIN/InGaN/GaN (Device B) HEMTs device parameters.

\begin{tabular}{|c|c|c|c|}
\hline Parameter & Unit & Device A & Device B \\
\hline 2DEG density $\left(n_{s}\right)$ & $\mathrm{cm}^{-2}$ & $2.6144 \times 10^{13}$ & $3.92 \times 10^{13}$ \\
\hline Carrier mobility $(\mu)$ & $\mathrm{cm}^{2} / \mathrm{v}-\mathrm{s}$ & 1425 & 1650 \\
\hline $\begin{array}{l}\text { Drain current } \\
\text { density (IDS) }\end{array}$ & $\mathrm{A} / \mathrm{mm}$ & 2.81 & 5.01 \\
\hline $\begin{array}{l}\text { Transconductance } \\
\left(\mathbf{G}_{M}\right)\end{array}$ & $\mathrm{S} / \mathrm{mm}$ & 0.669 & 0.72 \\
\hline $\begin{array}{l}\text { Gate voltage swing } \\
\text { (GVS) }\end{array}$ & $\mathrm{V}$ & 4 & 7 \\
\hline $\begin{array}{l}\text { Breakdown voltage } \\
\left(V_{B R}\right)\end{array}$ & $\mathrm{V}$ & 55.3 & 43.5 \\
\hline $\begin{array}{l}\text { Current gain cut-off } \\
\text { frequency }\left(F_{T}\right)\end{array}$ & $\mathrm{GHz}$ & 252 & 275 \\
\hline $\begin{array}{l}\text { Power gain cut-off } \\
\text { frequency }\left(\mathrm{F}_{\mathrm{MAX}}\right)\end{array}$ & $\mathrm{GHz}$ & 263 & 289 \\
\hline $\begin{array}{l}\text { Johnson Figure of } \\
\text { Merit }\left(J F o M=F_{T} x\right. \\
\left.V_{\text {BR }}\right)\end{array}$ & THz.V & 13.935 & 11.962 \\
\hline FMAX X VBR product & THz.V & 14.543 & 12.571 \\
\hline
\end{tabular}




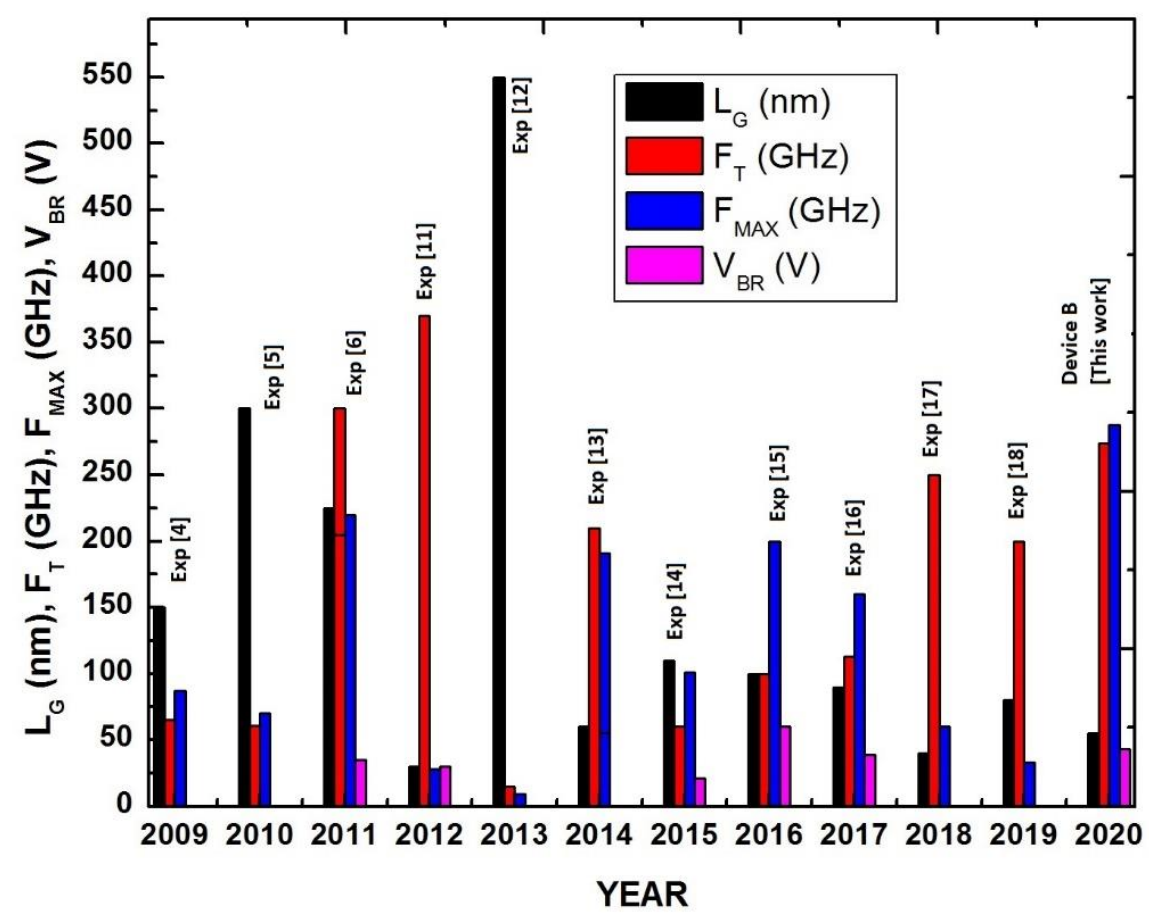

Figure 13. (a) Comparison of GaN-HEMTs performance.

\section{Conclusion:}

The composite channel InGaN/GaN-based HEMTs is proposed in this work for high linearity applications. The proposed HEMTs characteristics are analyzed using both AlGaN and InAlN barriers. The strong polarization, enhanced electron mobility, high linearity, high breakdown voltage, low short channel effects, excellent $\mathrm{V}_{\mathrm{BR}}$, and high $\mathrm{F}_{\mathrm{T}} / \mathrm{F}_{\mathrm{MAX}}$ demonstrated and the results are compared with existing $\mathrm{GaN}$ channel-based device. The composite channel-based InAlN/InGaN/GaN HEMTs shown high gate voltage swing (GVS) than AlGaN/InGaN/GaN HEMT, which indicates its potential for high power and high linear millimeter wave electronics such as satellite communications, 6G mobile communications, and millimeter-wave RADAR applications.

\section{Declaration}

Funding: Not applicable

Conflict of interest: We confirm that this work is original and has not been published elsewhere nor is it currently under consideration for publication elsewhere. We do not have any conflict of interest against this research article publication. 
Availability of data and material: Not included (confidential data)

Code availability: Not included (confidential data)

\section{References}

[1] 1.X. Yu, W. Hong, W. Wang, H. Tao and C. Ren, "A millimeter wave 11W GaN MMIC power amplifier," Proceedings of 2014 3rd Asia-Pacific Conference on Antennas and Propagation, Harbin, 2014, pp. 1342-1344, doi: 10.1109/APCAP.2014.6992771.

[2] 2.D. Schwantuschke et al., "Broadband GaN-Based Power Amplifier MMIC and Module for V-Band Measurement Applications," 2018 13th European Microwave Integrated Circuits Conference (EuMIC), Madrid, 2018, pp. 9-12, doi: 10.23919/EuMIC.2018.8539940.

[3] 3.Schwantuschke, Dirk Bruckner, Peter Quay, Rudiger Mikulla, Michael and Ambacher, Oliver 2013. High-Gain Millimeter-Wave AlGaN/GaN Transistors. IEEE Transactions on Electron Devices, Vol. 60, Issue. 10, p. 3112.

[4] J. W. Chung, O. I. Saadat, J. M. Tirado, X. Gao, S. Guo and T. Palacios, "Gate-Recessed InAlN/GaN HEMTs on $\mathrm{SiC}$ Substrate With $\mathrm{Al}_{2} \mathrm{O}_{3}$ Passivation," in IEEE Electron Device Letters, vol. 30, no. 9, pp. 904-906, Sept. 2009, doi: 10.1109/LED.2009.2026718.

[5] P. Kordos et al., "RF Performance of InAlN/GaN HFETs and MOSHFETs With $f_{T} \times L_{G}$ up to $21 \mathrm{GHz} \cdot \mu \mathrm{m}$ " in IEEE Electron Device Letters, vol. 31, no. 3, pp. 180-182, March 2010, doi: 10.1109/LED.2009.2038078.

[6] D. S. Lee et al., "245-GHz InAlN/GaN HEMTs With Oxygen Plasma Treatment," in IEEE Electron Device Letters, vol. 32, no. 6, pp. 755-757, June 2011, doi: 10.1109/LED.2011.2132751.

[7] F. Lecourt et al., "InAlN/GaN HEMTs on Sapphire Substrate With 2.9-W/mm Output Power Density at $18 \mathrm{GHz}$," in IEEE Electron Device Letters, vol. 32, no. 11, pp. 15371539, Nov. 2011, doi: 10.1109/LED.2011.2166949.

[8] D. S. Lee, X. Gao, S. Guo, D. Kopp, P. Fay and T. Palacios, "300-GHz InAlN/GaN HEMTs With InGaN Back Barrier," in IEEE Electron Device Letters, vol. 32, no. 11, pp. 1525-1527, Nov. 2011, doi: 10.1109/LED.2011.2164613.

[9] F. Lecourt et al., "RF performance of InAlN/AIN/GaN HEMTs on sapphire substrate," in Electronics Letters, vol. 47, no. 3, pp. 212-214, 3 February 2011, doi: 10.1049/el.2010.7512.

[10] S. Tirelli et al., "Fully Passivated AlInN/GaN HEMTs With ft/fmax of 205/220 GHz," in IEEE Electron Device Letters, vol. 32, no. 10, pp. 1364-1366, Oct. 2011, doi: 10.1109/LED.2011.2162087.

[11] Y. Yue et al., "InAlN/AIN/GaN HEMTs With Regrown Ohmic Contacts and $f_{t}$ of $370 \mathrm{GHz}$," in IEEE Electron Device Letters, vol. 33, no. 7, pp. 988-990, July 2012, doi: 10.1109/LED.2012.2196751.

[12] T. Huang, Z. J. Liu, X. Zhu, J. Ma, X. Lu and K. M. Lau, "DC and RF Performance of Gate-Last AlN/GaN MOSHEMTs on Si With Regrown Source/Drain," in 
IEEE Transactions on Electron Devices, vol. 60, no. 10, pp. 3019-3024, Oct. 2013, doi: 10.1109/TED.2013.2274656.

[13] Dong Seup Lee1, Zhihong Liu2, and Tomás Palacios1, GaN high electron mobility transistors for sub-millimeter wave applications Japanese Journal of Applied Physics 53, 100212 (2014), doi:10.7567/JJAP.53.100212.

[14] C. Tsou, C. Lin, Y. Lian and S. S. H. Hsu, "101-GHz InAlN/GaN HEMTs on Silicon With High Johnson's Figure-of-Merit," in IEEE Transactions on Electron Devices, vol. 62, no. 8, pp. 2675-2678, Aug. 2015, doi: 10.1109/TED.2015.2439699.

[15] D. Xu et al., "0.1- $\mu \mathrm{m}$ InAlN/GaN High Electron-Mobility Transistors for Power Amplifiers Operating at 71-76 and 81-86 GHz: Impact of Passivation and Gate Recess," in IEEE Transactions on Electron Devices, vol. 63, no. 8, pp. 3076-3083, Aug. 2016, doi: 10.1109/TED.2016.2579160.

[16] H. Zhou et al., "DC and RF Performance of AlGaN/GaN/SiC MOSHEMTs With Deep Sub-Micron T-Gates and Atomic Layer Epitaxy $\mathrm{MgCaO}$ as Gate Dielectric," in IEEE Electron Device Letters, vol. 38, no. 10, pp. 1409-1412, Oct. 2017, doi: 10.1109/LED.2017.2746338.

[17] W. Xing et al., "InAlN/GaN HEMTs on Si With High $\mathrm{f}_{\mathrm{T}}$ of $250 \mathrm{GHz}$," in IEEE Electron Device Letters, vol. 39, no. 1, pp. 75-78, Jan. 2018, doi: 10.1109/LED.2017.2773054.

[18] Peng Cui et al., High-performance InAlN/GaN HEMTs on silicon substrate with high fT $\times$ Lg, Applied Physics Express 12, 104001 (2019), doi:10.7567/18820786/ab3e29.

[19] L. Li et al., "GaN HEMTs on Si With Regrown Contacts and Cutoff/Maximum Oscillation Frequencies of 250/204 GHz," in IEEE Electron Device Letters, vol. 41, no. 5, pp. 689-692, May 2020, doi: 10.1109/LED.2020.2984727.

[20] $\quad$ Fmax $=270 \mathrm{GHz}$ InAlN/GaN HEMT on Si with forming gas/nitrogen two-step annealing Peng Cui, Meng Jia, Guangyang Lin, Jie Zhang, Lars Gundlach, Yuping Zeng. May 2020, Applied Physics, doi: arXiv:2005.08422.

[21] T. Palacios, S. Rajan, A. Chakraborty, S. Heikman, S. Keller, S. P. DenBaars, and U. K. Mishra, "Influence of the dynamic access resistance in the $\mathrm{g} m$ and $\mathrm{f} T$ linearity of AlGaN/GaN HEMTs," IEEE Trans. Electron Devices, vol. 52, no. 10, pp. 2117-2123, Oct. 2005 .

[22] D. W. DiSanto, and C. R. Bolognesi, "At-bias extraction of access parasitic resistances in AlGaN/GaN HEMTs: Impact on device linearity and channel electron velocity," IEEE Trans. Electron Devices, vol. 53, no. 12, pp. 2914-2919, Dec. 2006.

[23] R. J. Trew, Y. Liu, G. L. Bilbro, W. Kuang, R. Vetury, and J. B. Shealy, "Nonlinear source resistance in high-voltage microwave AlGaN/GaN HFETs," IEEE Trans. Microw. Theory Tech., vol. 54, no. 5, pp. 2061-2067, May 2006.

[24] T. Fang, R. Wang, H. Xing, S. Rajan, and D. Jena, "Effect of optical phonon scattering on the performance of GaN transistors," IEEE Electron Devices Lett., vol. 33, no. 5, pp. 709-711, May 2012.

[25] J. Liu, Y. Zhou, R. Chu, Y. Cai, K. J. Chen, and K. M. Lau, "Al0. 3Ga0.7N/Al0. 05GaN0. 95N/GaN composite-channel HEMTs with enhanced linearity," in Proc. IEDM Tech., 2004, pp. 811-814.

[26] J. Kuzmik, P. Javorka, A. Alam, M. Marso, M. Heuken, and P. Kordos, "Determination of channel temperature in $\mathrm{AlGaN} / \mathrm{GaN}$ HEMTs grown on sapphire and 
silicon substrates using DC characterization method," IEEE Trans. Electron Devices, vol. 49, no. 8, pp. 1496-1498, Aug. 2002.

[27] B. K. Ridley, W. J. Schaff, and L. F. Eastman, "Hot-phononinduced velocity saturation in GaN," J. Appl. Phys., vol. 96, no. 3, pp. 1499-1502, Aug. 2004.

[28] K. Shinohara, D. Regan, A. Corrion, D. Brown, Y. Tang, J. Wong, G. Candia, A. Schmitz, H. Fung, S. Kim, and M. Micovic, "Selfaligned-gate GaN HEMTs with heavilydoped n+-GaN ohmic contacts to 2DEG," in Proc. IEEE Int. Electron Devices Meeting, Dec. 2012, pp. 617-620.

[29] W. Xing et al., "InAlN/GaN HEMTs on Si With High $\mathrm{f}_{\mathrm{T}}$ of $250 \mathrm{GHz}$," in IEEE Electron Device Letters, vol. 39, no. 1, pp. 75-78, Jan. 2018, doi: 10.1109/LED.2017.2773054.

[30] Yachao Zhang et al., High performance InGaN double channel high electron mobility transistors with strong coupling effect between the channels, Appl. Phys. Lett. 113, 233503 (2018); doi: 10.1063/1.5051685.

[31] O. Laboutin, Y. Cao, W. Johnson, R. Wang, G. Li, D. Jena, and H. Xing, InGaN channel high electron mobility transistor structures grown by metal organic chemical $\begin{array}{lllll}\text { vapor } & \text { deposition, } & \text { Appl. } & \text { Phys. } & \text { Lett. 100, }\end{array}$ (2012); https://doi.org/10.1063/1.3697415.

[32] G. Simin et al., "SiO/AlGaN/InGaN/GaN MOSDHFETs," in IEEE Electron Device Letters, vol. 23, no. 8, pp. 458-460, Aug. 2002, doi: 10.1109/LED.2002.801316.

[33] Ankush Bag, Shubhankar Majumdar, Subhashis Das, Dhrubes Biswas, Probing InGaN immiscibility at $\mathrm{AlGaN} / \mathrm{InGaN}$ heterointerface on silicon (111) through two-step capacitance-voltage and conductance-voltage profiles, Materials \& Design (2017), doi: 10.1016/j.matdes.2017.07.061

[34] GHz Ronghua Wang1, Guowang Li1, Golnaz Karbasian1, Jia Guo1, Faiza Faria1, Zongyang Hu1, Yuanzheng Yue1, Jai Verma1, Oleg Laboutin2, Yu Cao2, Wayne Johnson2, Gregory Snider1, Patrick Fay1, Debdeep Jena1, and Huili (Grace) Xing, InGaN Channel High-Electron-Mobility Transistors with InAlGaN Barrier and fT/fmax of 260/220, Applied Physics Express 6 (2013) 016503, http://dx.doi.org/10.7567/APEX.6.016503

[35] Ambacher, O.; Majewski, J.; Miskys, C.; Link, A.; Hermann, M.; Eickho_, M.; Stutzmann, M.; Bernardini, F.; Fiorentini, V.; Tilak, V.; et al. Pyroelectric properties of $\mathrm{Al}$ (In) GaN/GaN hetero-and quantum well structures. J. Phys. Condens. Matter 2002, 14, 3399-3434. doi:10.1088/0953-8984/14/13/302.

[36] T. Inoue et al., "Polarization Engineering on Buffer Layer in GaN-Based Heterojunction FETs," in IEEE Transactions on Electron Devices, vol. 55, no. 2, pp. 483488, Feb. 2008, doi: 10.1109/TED.2007.912367.

[37] Li, C.; Li, Z.; Peng, D.; Ni, J.; Pan, L.; Zhang, D. Improvement of breakdown and current collapse characteristics of GaN HEMT with a polarization-graded AlGaN buffer. Semicond. Sci. Technol. 2015, 30, 035007. doi: 10.1088/0268-1242/30/3/035007.

[38] Piprek, J., Semiconductor Optoelectronic Devices: Introduction to Physics and Simulation. UCSB: Academic Press (2003): 22.

[39] Kaikai Liu and Xiaohang Li, Polarization properties of wurtzite III nitride indicate the principle of polarization engineering, Applied Physics, Jan 2020. doi:arXiv:1808.07211. 
[40] SILVACO Int. ATLAS User's Manual; Device Simulation Software: Santa Clara, CA, USA, 2016; Available online: https://www.silvaco.com.

[41] S. Adachi, Properties of Semiconductor Alloys: Group-IV, III-V and II-VI Semiconductors. Chichester: Wiley, 2008.

[42] Giovanni C, Dongping X, D. M Schreurs, Accurate Multibias Equivalent-Circuit Extraction for GaN HEMTs. IEEE Trans Microwave Theory Tech, 2006; 54, 3616-3622. doi:10.1109/TMTT.2006.882403. 
(a)

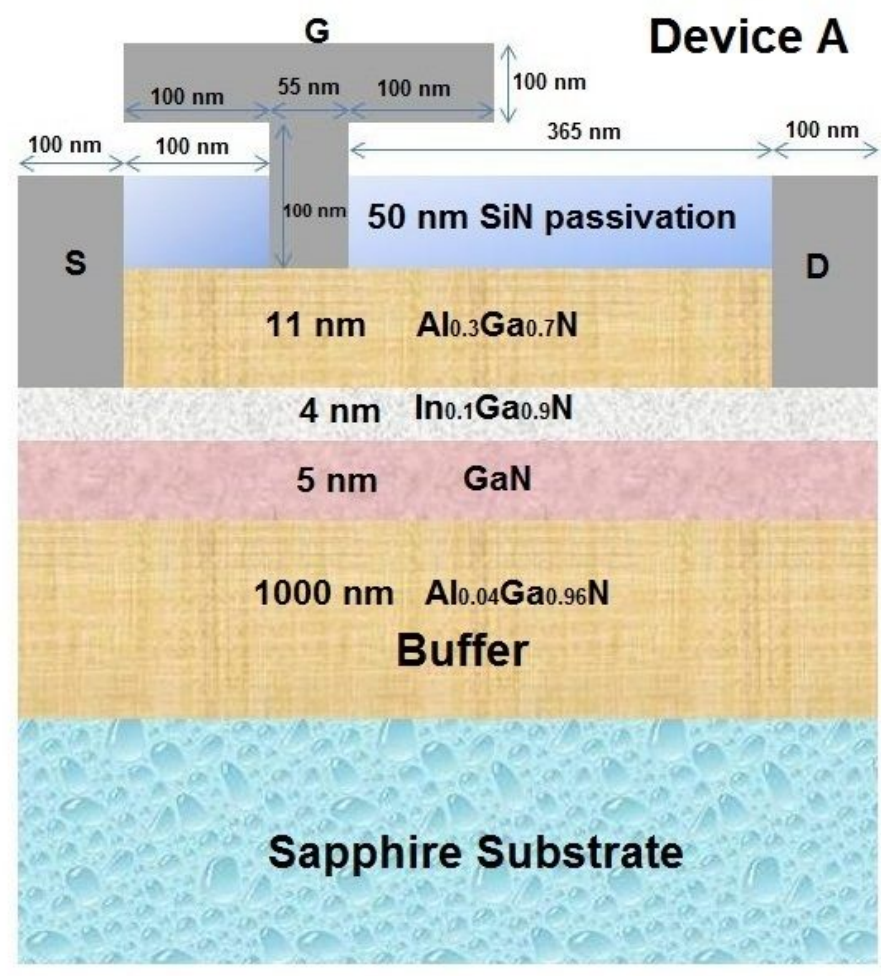

(b)

G Device B

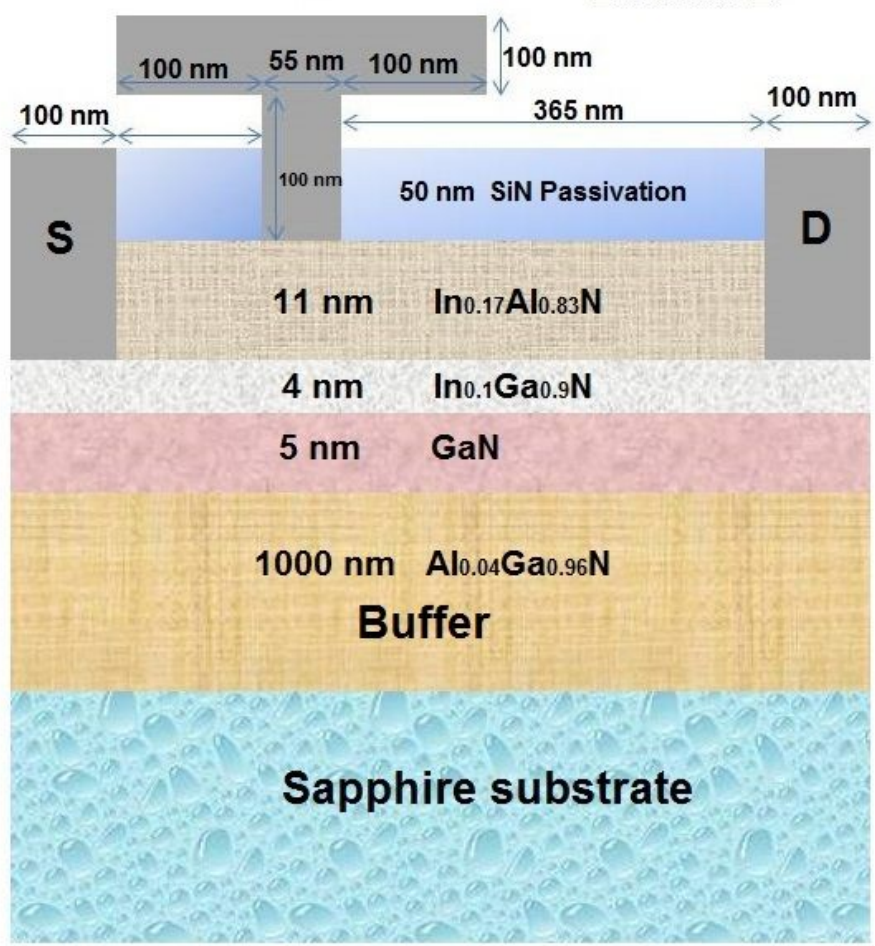

Figure 1

(a) Proposed device A (b) Proposed device B
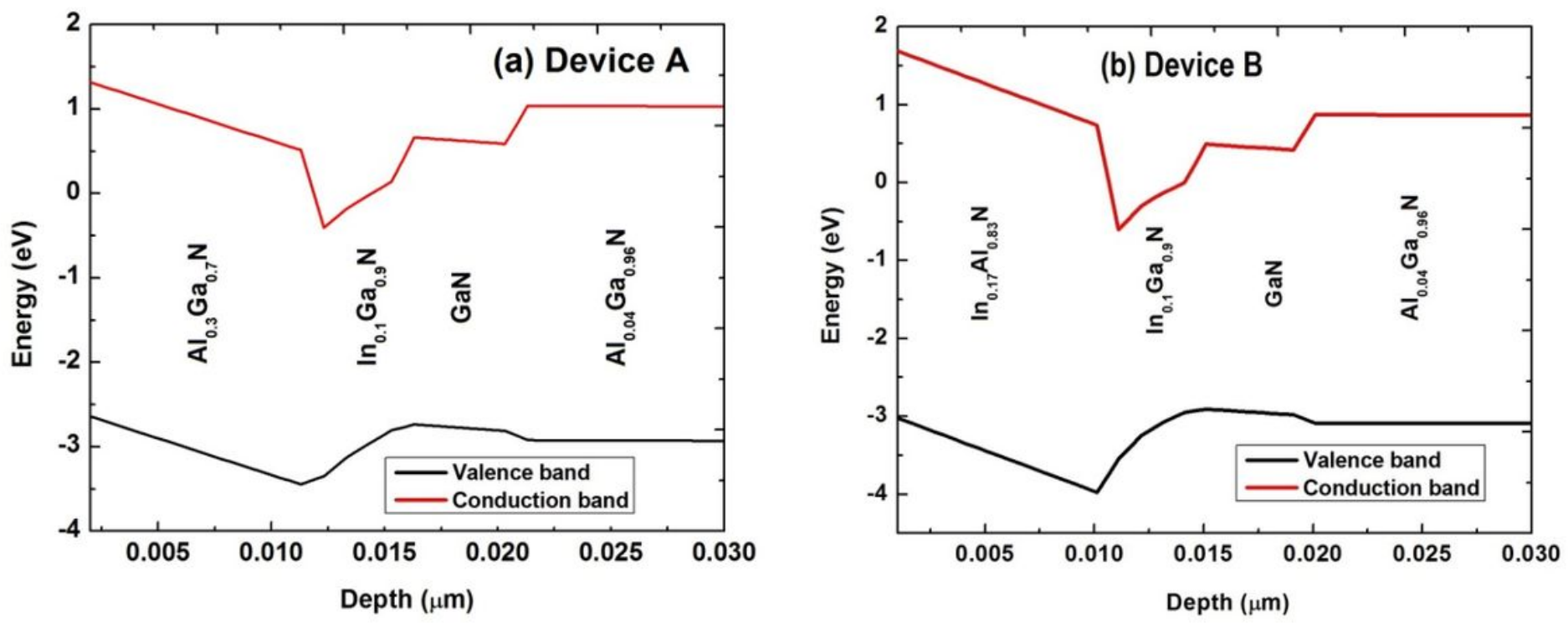

Figure 2 
(a) Band diagram of Device A (b) Band diagram of Device B
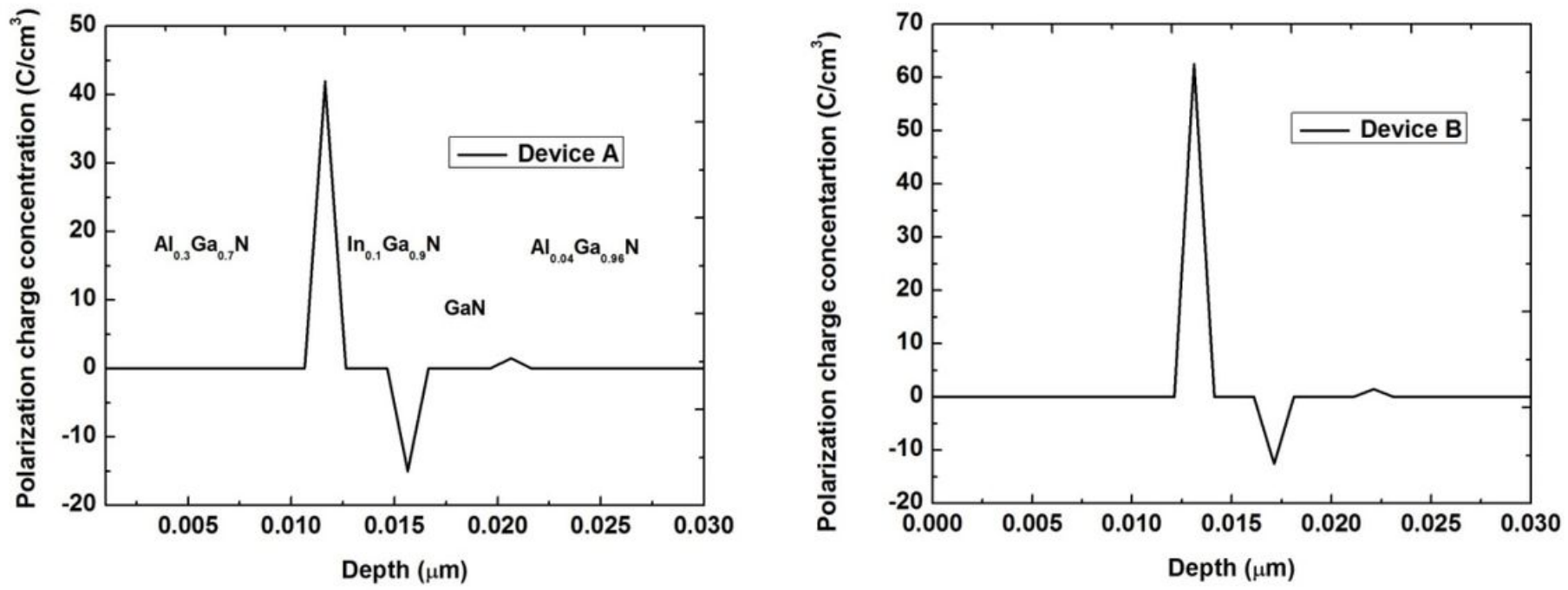

Figure 3

Polarization charge details of (a) AlGaN/InGaN/GaN/AIGaN heterostructure (b) InAIN/InGaN/GaN/AIGaN heterostructure

(a)

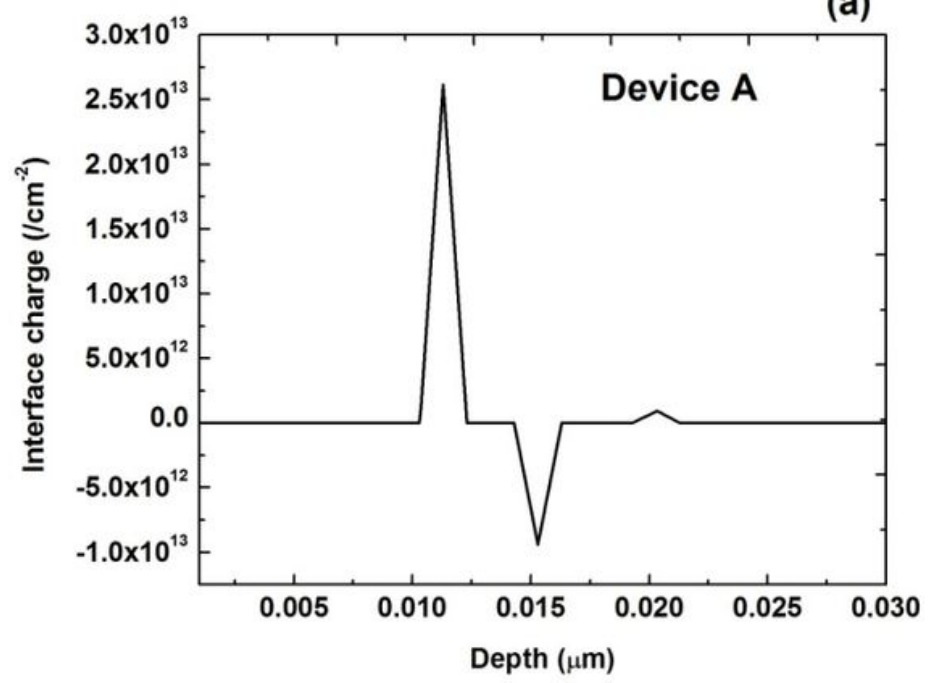

(b)

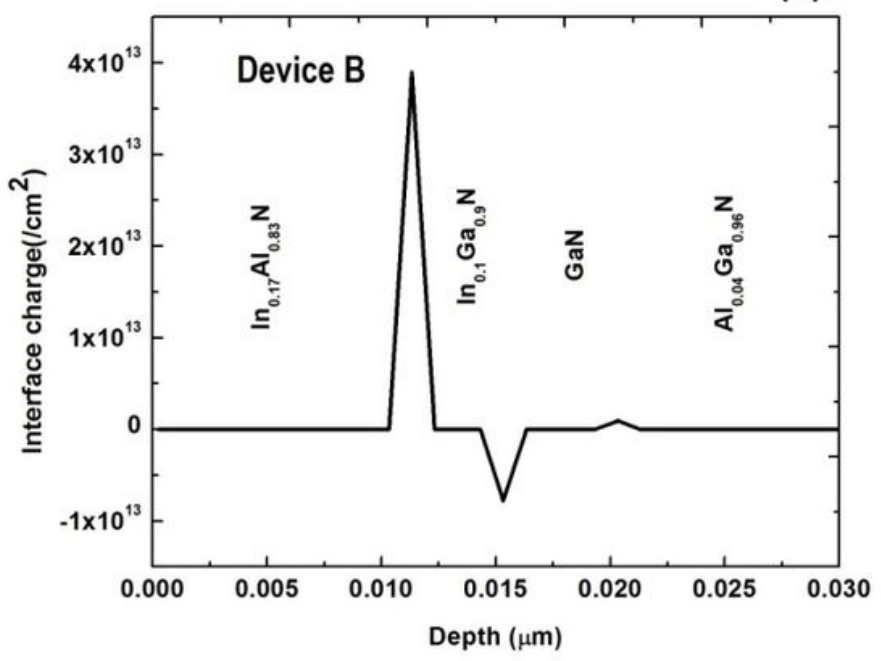

Figure 4

Interface charge details of (a) Device A (b) Device B 
(a)

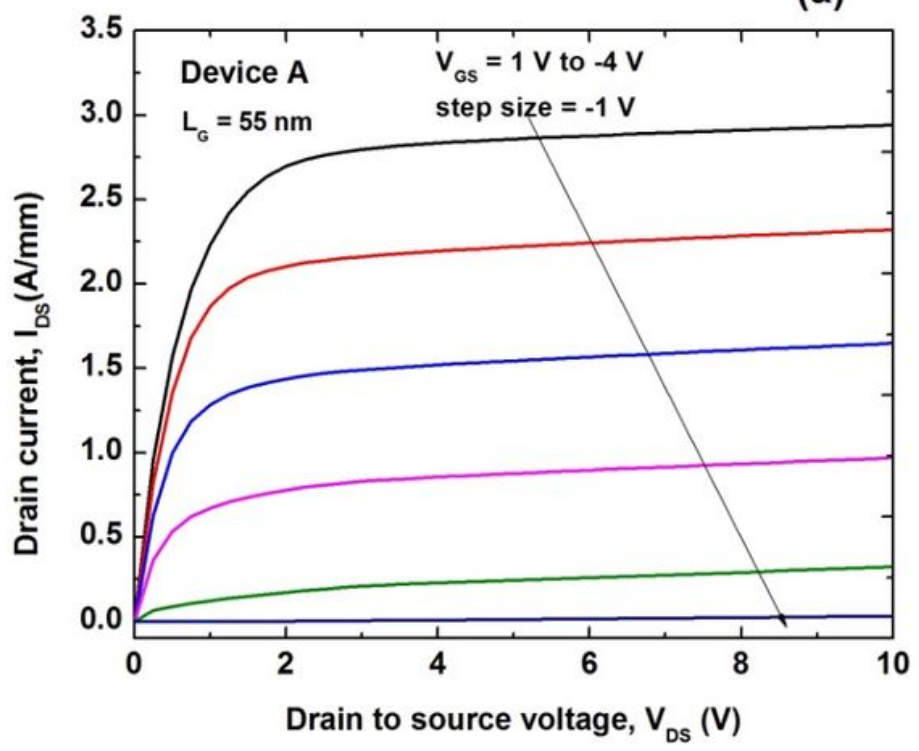

Figure 5

I-V characteristics of Lg 55 nm HEMTs

(a)

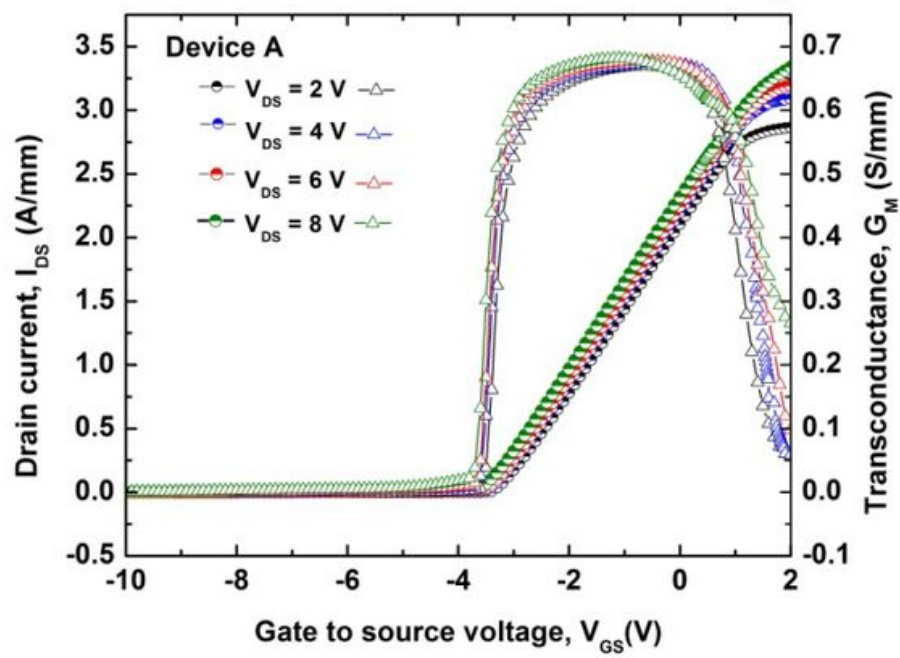

Figure 6

Transconductance characteristics of Lg 55 nm HEMTs (b)

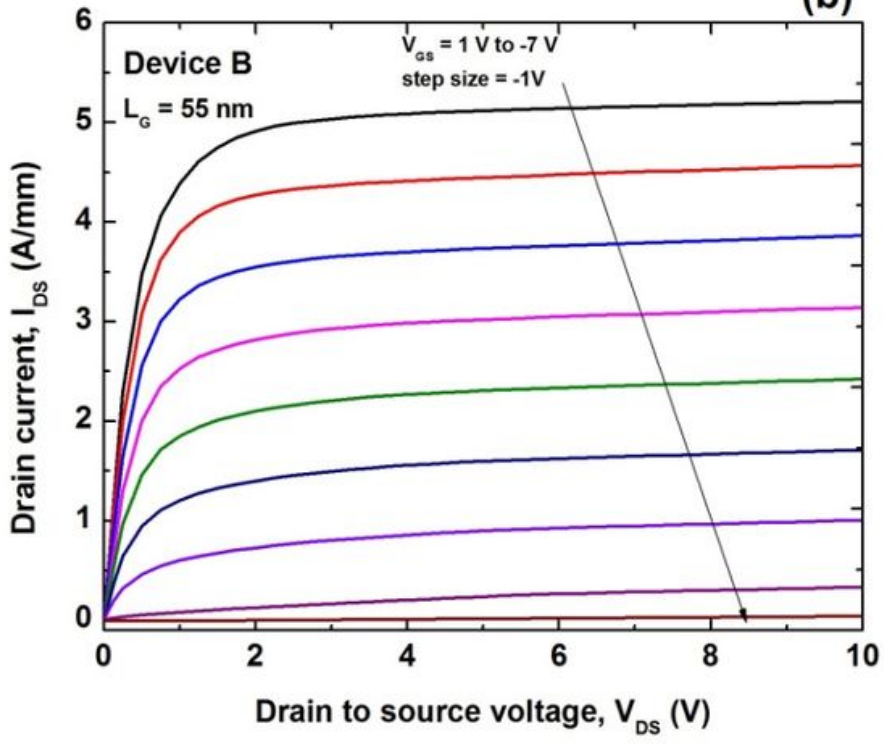

(b)

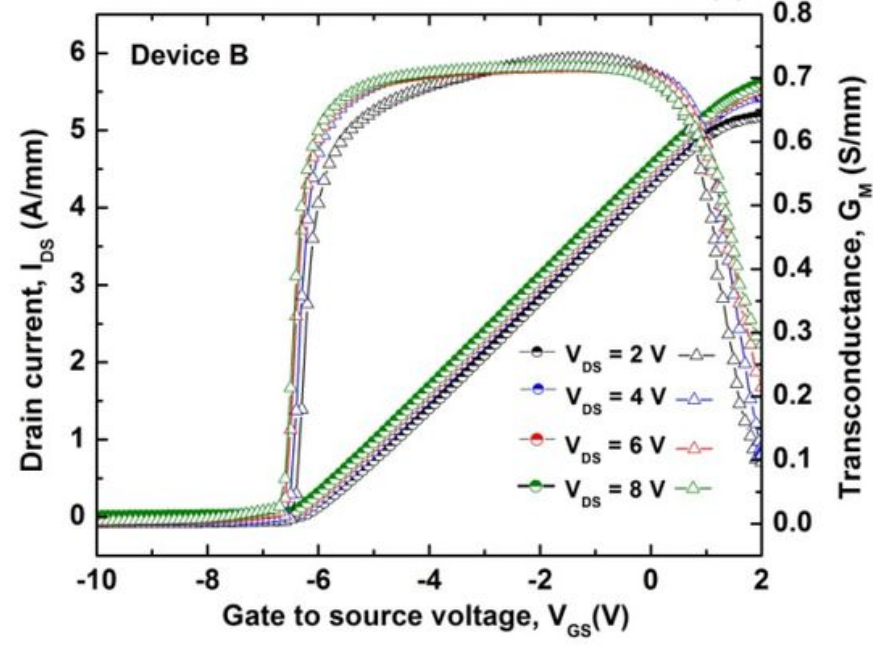


(a)

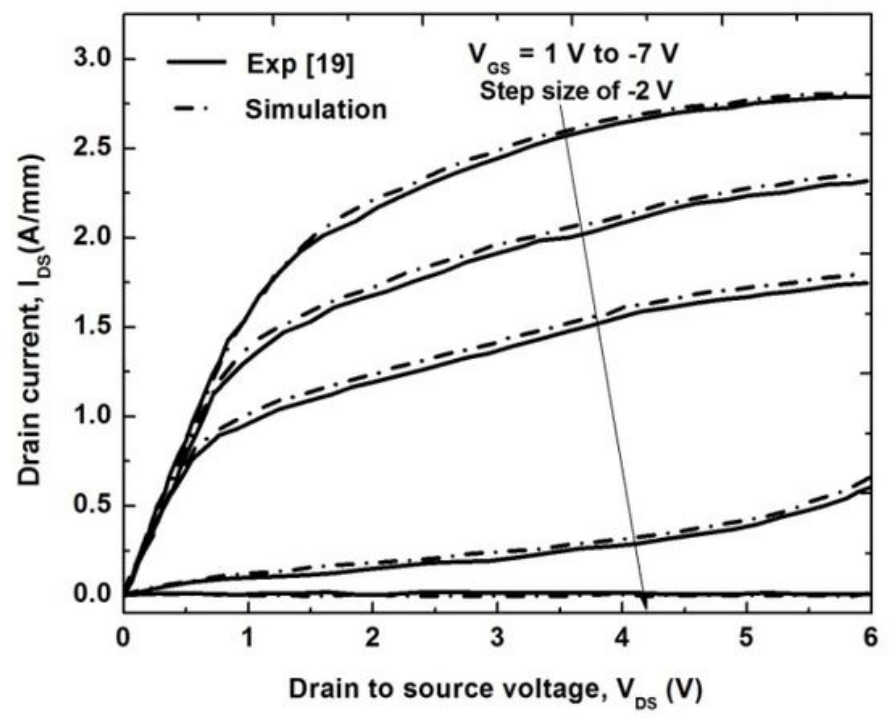

(b)

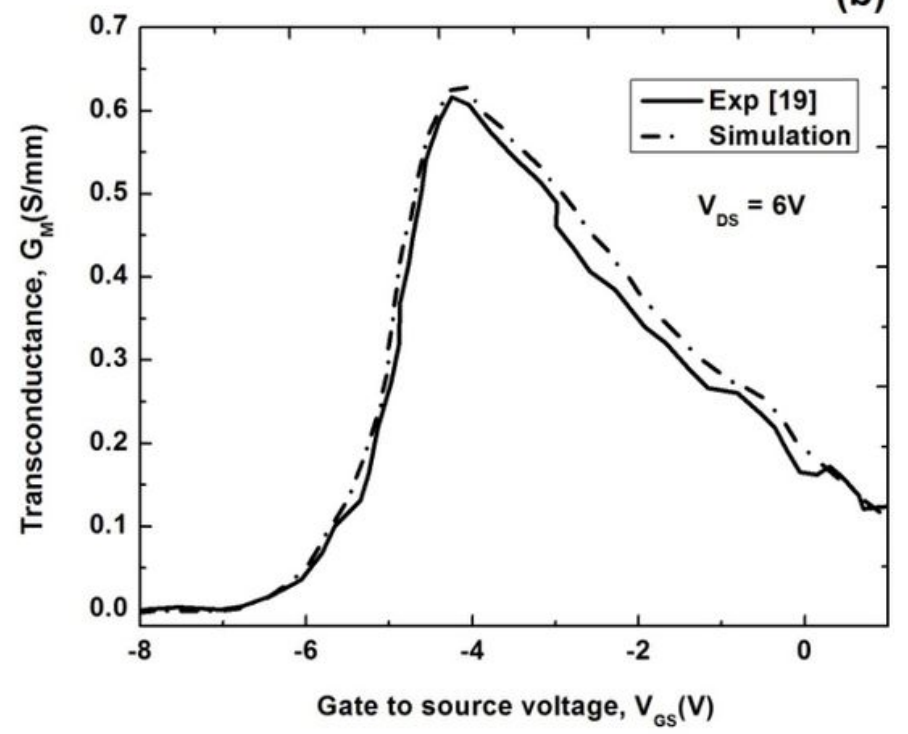

Figure 7

(a) Simulation and experimental results for V-I characteristics [19], (b) Simulation and experimental results for transconductance characteristics [19].

(a)

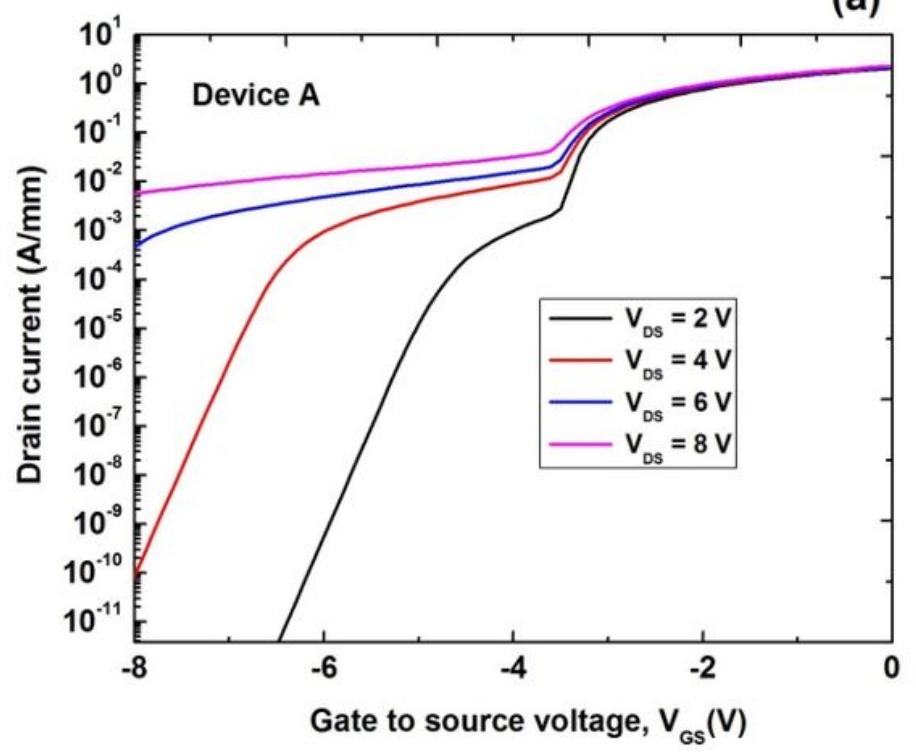

(b)

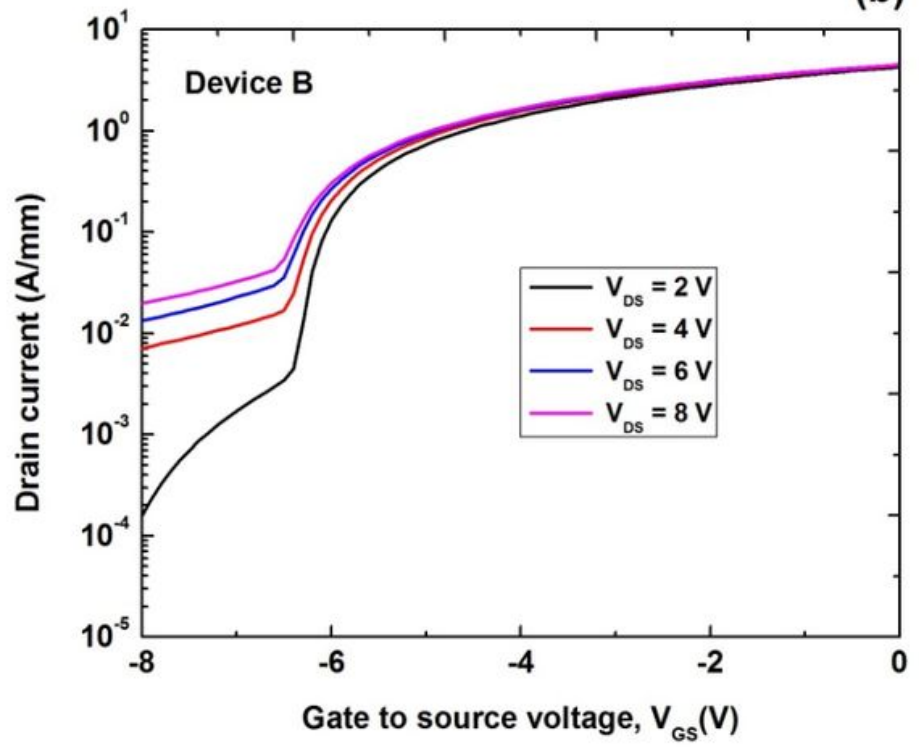

Figure 8

Log-scale plot of IDS-VGS of Lg 55 nm HEMTs 


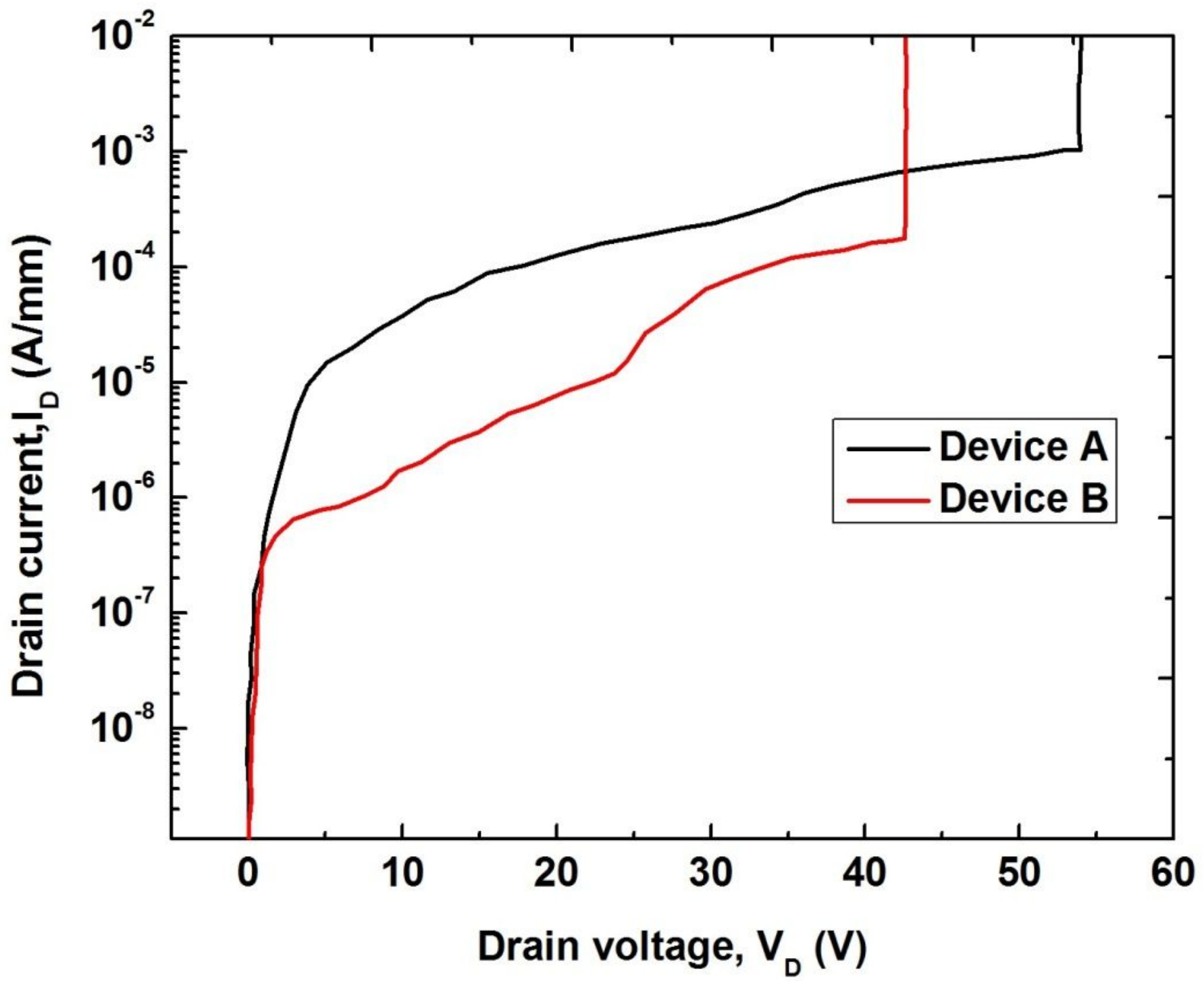

Figure 9

Breakdown characteristics 

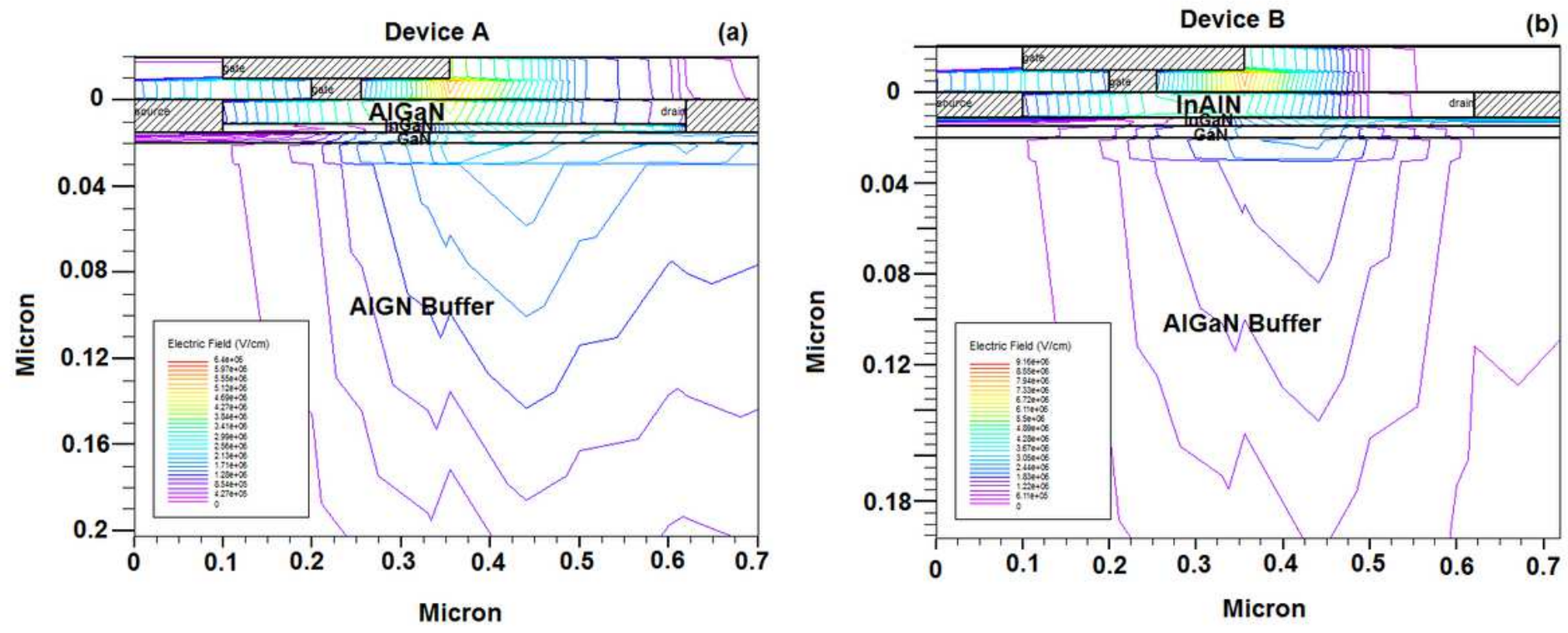

Figure 10

Electric field distribution at breakdown condition.
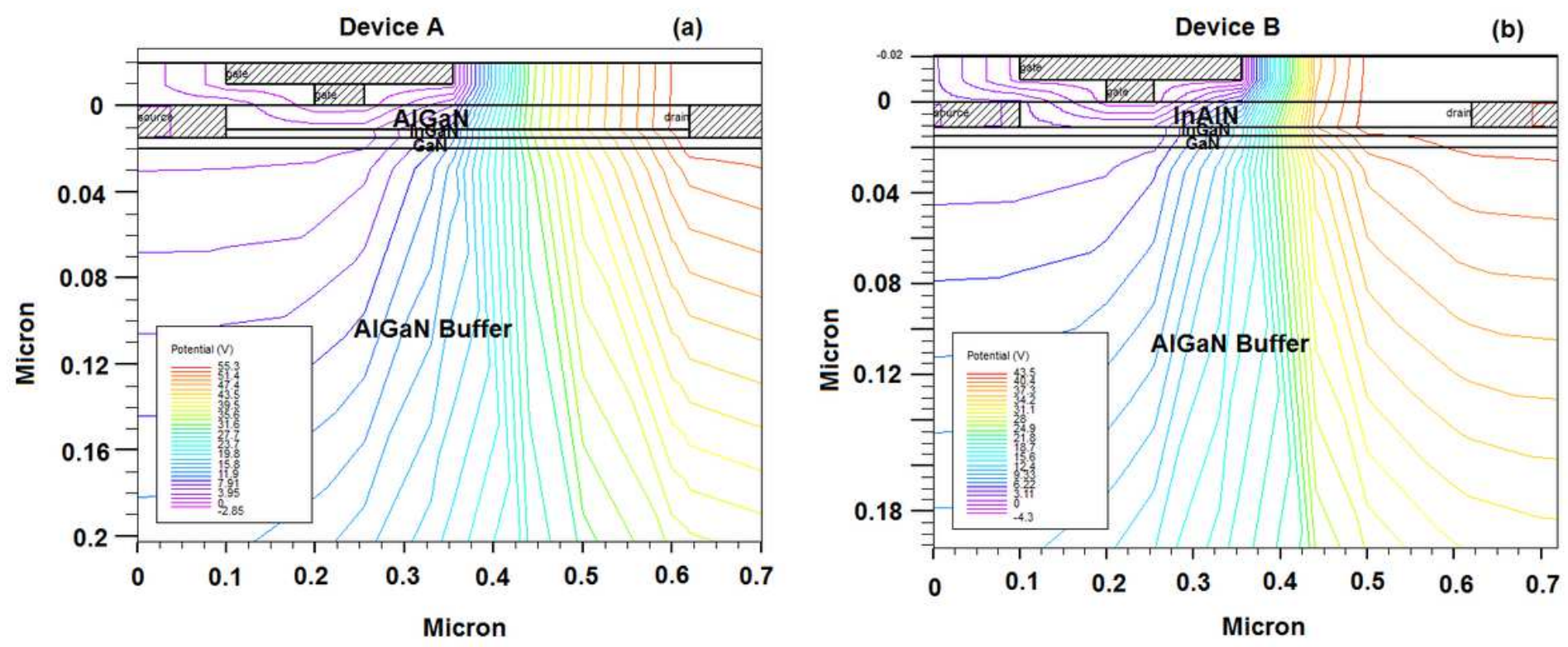

Figure 11

Potential distribution at breakdown condition 
(a)

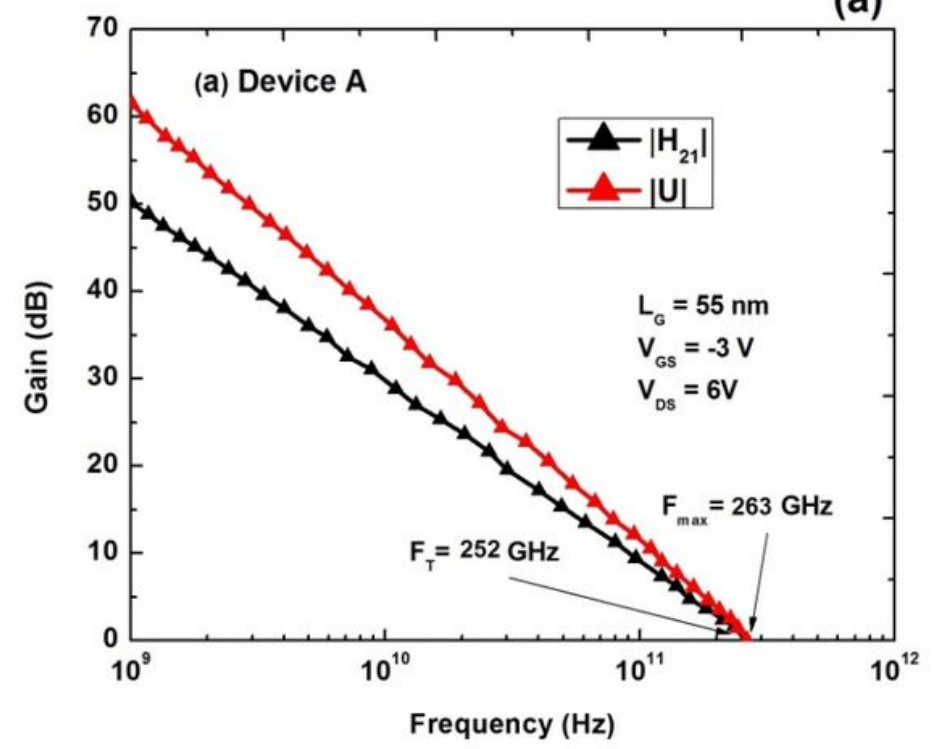

(b)

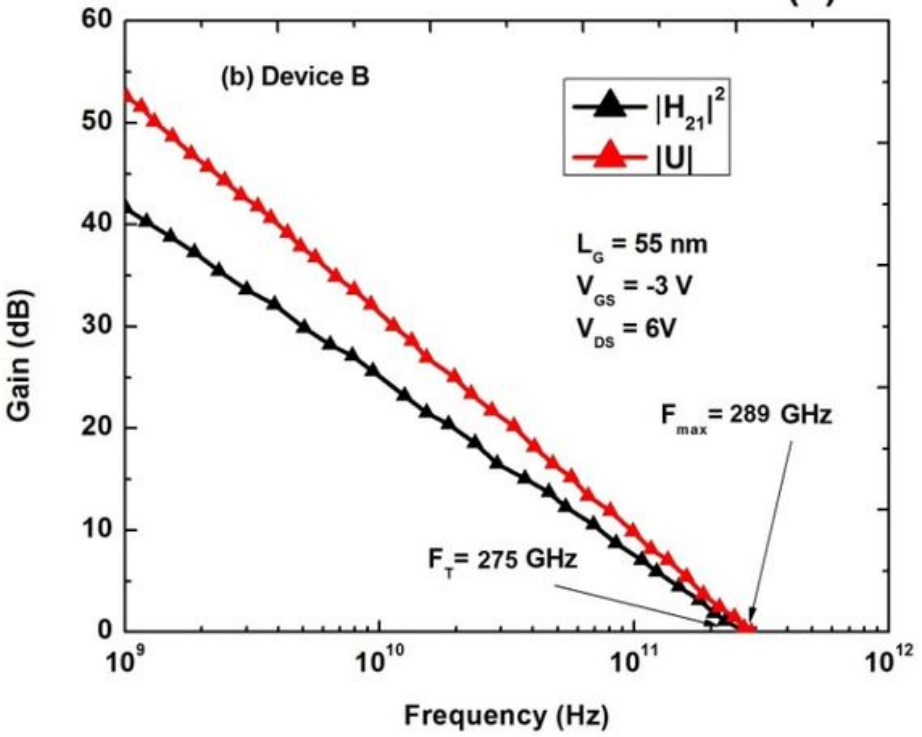

Figure 12

(a) Microwave performance of Lg $55 \mathrm{~nm}$ HEMTs 


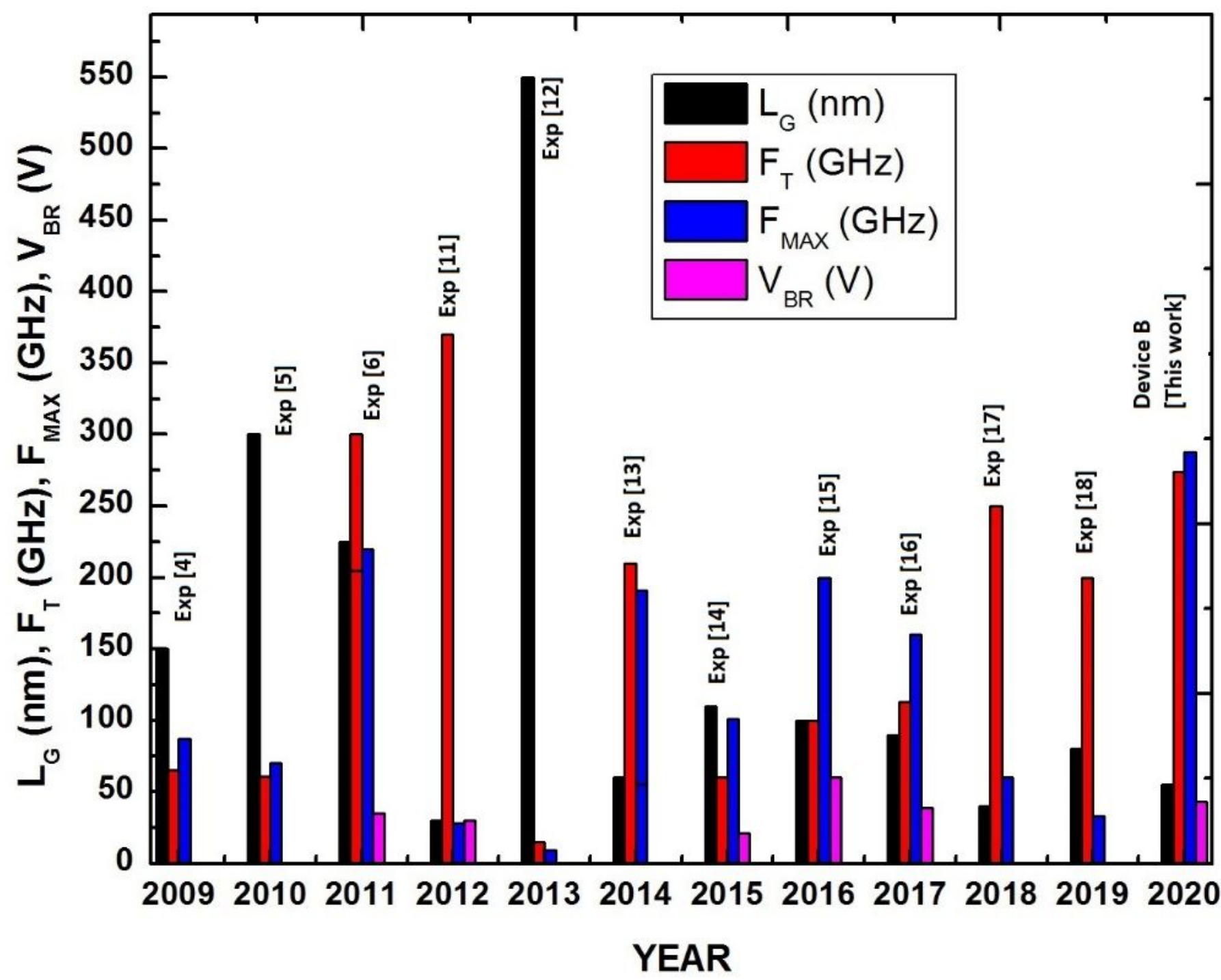

Figure 13

(a) Comparison of GaN-HEMTs performance. 